\title{
INFLUÊNCIA DA NUTRIÇÃO EM MULHERES COM ENDOMETRIOSE: REVISÃO DE LITERATURA
}

\section{ARTIGO DE REVISÃO}

GONÇALVES, Dryele Silva ${ }^{1}$, SILVA, Yone Da ${ }^{2}$, NEVES, Carlos Eduardo Da ${ }^{3}$, MARINHO-CARVALHO, Mônica Mesquita ${ }^{4}$

GONÇALVES, Dryele Silva. Et al. Influência da nutrição em mulheres com endometriose: revisão de literatura. Revista Científica Multidisciplinar Núcleo do Conhecimento. Ano 06, Ed. 06, Vol. 17, pp. 73-108. Junho de 2021. ISSN: 2448-0959, Link de acesso: https://www.nucleodoconhecimento.com.br/nutricao/nutricao-emmulheres, DOI: 10.32749/nucleodoconhecimento.com.br/nutricao/nutricao-emmulheres

\section{RESUMO}

Contexto da pesquisa: Endometriose é uma doença ginecológica caracterizada por implantes endometriais benignos fora do útero podendo atingir diferentes locais acometendo exclusivamente mulheres em fase reprodutiva. Sua incidência varia em torno de $15 \%$ nas mulheres. As pacientes podem não apresentar nenhuma sintomatologia, mas a maior parte das mulheres apresentam sintomas que afetam de forma negativa o bem-estar como, fadiga crônica, dor pélvica crônica, dismenorreia e em casos mais agravado da doença a infertilidade pode estar presente. No entanto, até o momento, a sua etiopatogenia não está bem esclarecida e não existe uma teoria única que possa identificar e explicar todas as condições clínicas da doença que são consideradas multifatoriais como aspectos genéticos, imunológicos, hormonais e também aspectos nutricionais. Objetivos: $O$ objetivo da seguinte revisão é analisar a interferência da nutrição em mulheres portadoras de endometriose e investigar se um

\footnotetext{
${ }^{1}$ Graduada no curso de Nutrição - Universidade Veiga de Almeida.

${ }^{2}$ Doutora em Ciências (UFF).

${ }^{3}$ Mestre em Saúde Materno Infantil (UFF).

${ }^{4}$ Doutora em Bioquímica (IQ - UFRJ) e Pós Doutorado em Enzimologia (UFRJ). 
tratamento nutricional adequado pode ser benéfico para as mulheres com essa patologia. Problema: Sabe-se que o protocolo de um tratamento medicamentoso para essa condição se faz totalmente necessário para o controle da doença, entretanto por ser uma patologia que causa processos inflamatórios a nutrição é uma boa aliada para um tratamento alternativo. Assim, a questão deste estudo é: A boa nutrição em mulheres com endometriose pode auxiliar de forma positiva na diminuição de inflamação, dores crônicas e consequentemente a melhora da qualidade de vida? Metodologia: Para este trabalho, realizou-se uma revisão bibliográfica, através de pesquisa qualitativa e exploratória, utilizando as bases de dados da Biblioteca Virtual em Saúde (BVS), Scientific Electronic Library Online (Scielo), Google Acadêmico, Google Livros e PubMed com pesquisas publicadas no período de 2015 a 2020 . Resultados principais: Um tratamento nutricional adequado e individualizado com alimentos antioxidantes, anti-inflamatórios podem beneficiar mulheres com endometriose a diminuir processos inflamatórios e dores crônicas tornando possível a oportunidade de mais uma opção de tratamento para controle da doença e melhora da qualidade de vida.

Palavras-chave: aspectos nutricionais, endometriose, antioxidantes, dor pélvica, dietoterapia.

\section{INTRODUÇÃO}

A endometriose é definida como a presença de tecido endometrial na cavidade externa do útero e que pode se instalar em qualquer parte do corpo como intestino, bexiga, ovários entre outros, induzindo uma reação inflamatória e crônica (VERCELLINI et al., 2014).

A suspeita de endometriose é levantada através de anamnese, exame físico além de exames complementares, como ultrassonografia e ressonância magnética afim de encontrar possíveis focos da doença. Sua prevalência na população em geral é difícil de quantificar porque o diagnóstico definitivo requer visualização cirúrgica por videolaparoscopia que é considerado o padrão-ouro. Entretanto mesmo com essa limitação, um estudo feito com 1.486 mulheres submetidas à sua primeira investigação 
laparoscópica em dez países, concluiu que a endometriose é um problema global comum, com uma incidência variando de 35\% a 100\% em casos sintomáticos (HSU et al., 2010; NNOAHAM et al., 2011).

De Marqui (2014), diz que a prevalência nas mulheres no período reprodutivo varia de 5 a 15\% e no caso de mulheres no processo de pós-menopausa esse valor é de em torno $3 \%$ e ainda se fôssemos mensurar mulheres com quadro de infertilidade, a endometriose corresponde em até $60 \%$ dessas mulheres. Estima-se que aproximadamente em todo o mundo 70 milhões de mulheres sejam afetadas pela endometriose ao que corresponde como sendo um dos principais motivos de internação nos países mais desenvolvidos (BENTO; MOREIRA, 2017).

Em relação ao quadro clínico da endometriose, a mesma não tem cura. A sintomatologia da doença pode se manifestar de forma diferente entre as mulheres e com diversas intensidades, existindo também mulheres assintomáticas que varia de 3 a $22 \%$. Os sintomas mais comuns e estudados são: dismenorreia (cólicas menstruais que antecede o período menstrual ou durante o período), menstruação com irregularidade, infertilidade, dor pélvica crônica (DPC), dispareunia (episódio de dor no ato sexual) e distúrbios da defecação como por exemplo, constipação, diarreia e sangramento (DE MARQUI, 2014; GOLFIER et al., 2018; JURKIEWICZPRZONDZIONO et al., 2017).

De um modo geral, a presença de sintomas como a DPC leva a uma qualidade de vida baixa e uma saúde mental comprometida, a endometriose está associada a uma alta morbidade (FACCHIN et al., 2015; SCHINK et al., 2019).

Como recurso terapêutico da endometriose, o método mais eficaz que tem se mostrado para diminuição dos sintomas é a cirurgia. Alguns estudos atribuíram de forma positiva para redução da dispareunia, dismenorreia, e principalmente da DPC após seis meses a um ano da realização do procedimento cirúrgico, contribuindo com uma melhora significativa do bem-estar dessas mulheres (MABROUK et al., 2011; PORTO et al., 2015; SETALA et al., 2012). 
Além da cirurgia, é possível obter sucesso em relação a redução dos sintomas através de tratamentos farmacológicos hormonais com os anticoncepcionais orais e também com auxílio da dietoterapia (NACUL; SPRITZER, 2010).

Esta é uma enfermidade decorrente de muitos fatores. Apesar de existir diferentes teorias sobre a etiologia e patologia como por exemplo a teoria da menstruação retrógrada, os mecanismos exatos ainda não foram totalmente compreendidos, porém existem vários parâmetros incluindo aspectos imunológicos, mediadores inflamatórios, genética, estresse oxidativo e fatores ambientais que são discutidos como sendo fatores de influência (VERCELLINI et al., 2014; MACER; TAYLOR, 2012; KAUR; ALLAHBADIA, 2016).

Algumas condições como o estresse, vida sedentária, ansiedade e poluição faz com que os radicais livres circulantes no sangue aumentem, favorecendo o estresse oxidativo e contribuindo assim para a patogenia da endometriose. Ainda assim, dentre os fatores ambientais, vale a pena enfatizar a dieta que tem sido pouco estudada, e sua relação com a doença (PORFÍRIO et al., 2017).

Alguns estudos descrevem que mulheres que adotam mudanças no hábito de vida focando principalmente em uma alimentação saudável, livre de lactose, glúten e cafeína e sobretudo com alto teor de vegetais, frutas e sem alimentos com alto teor de estrogênio pode beneficiar-se do uso dessa terapia complementar. O papel da nutrição na endometriose ganhou foco nos últimos anos, uma vez que se observou que a dieta pode ser capaz de afetar vários processos envolvidos na doença incluindo inflamação, metabolismo das prostaglandinas, atividade de estrogênio (KARLSSON et al., 2019).

Conforme dito por Cambiaghi e De Souza Rosa (2016, p.14) "[...] A alimentação é a necessidade mais primitiva dos indivíduos e tem ações tanto para o bem, quando for bem cuidada, como para o mal, quando for inapropriada. Isso é uma realidade".

Dadas essas análises teóricas preliminares, busca-se, portanto, demonstrar através de revisão bibliográfica com fundamentos em trabalhos científicos a importância do 
efeito da nutrição na ocorrência e progressão da endometriose e elucidar como uma alimentação equilibrada pode reduzir as manifestações clínicas da doença. Por se tratar de uma doença com alta incidência e, contudo, de caráter progressivo, a mesma quando caracterizada sintomática causa um enorme abalo na vida das pacientes.

\section{MATERIAIS E MÉTODOS}

Este trabalho trata-se de uma pesquisa bibliográfica de caráter qualitativo e exploratório, a busca ocorreu nos meses de março a outubro de 2020, englobando monografias, livros, teses de mestrado e revistas acadêmicas eletrônicas. Foi efetuada uma extensa busca nas bases científicas eletrônicas Biblioteca Virtual em Saúde (BVS), Scientific Electronic Library Online (Scielo), Google Acadêmico, Google Livros e PubMed. Durante a busca de artigos foram empregadas as seguintes palavras-chave: aspectos nutricionais, endometriose, antioxidantes, dor pélvica e dietoterapia, doença crônica e dieta, endometriose e vitaminas, Zinco e endometriose, resveratrol e doença crônica, fisiopatologia da endometriose e tratamentos da endometriose.

Inicialmente, os artigos científicos foram selecionados com base nos títulos e resumos exibidos após a busca eletrônica. Considerou-se como método de inclusão estudos publicados em um período de cinco anos que dispunham ligação direta com o tema, bem como a disposição da versão completa, escritos em português, inglês, russo e alemão. Além disso, foram verificadas as referências para determinar outros estudos que fossem capazes de serem incluídos neste trabalho.

\section{REVISÃO DE LITERATURA}

\subsection{ENDOMETRIOSE}

A endometriose é uma enfermidade crônica inflamatória benigna que depende de estrogênio, que por sua parte favorece o crescimento do tecido endometrial (mucosa que reveste o útero) fora do útero caracterizando presença de implantes endometriais ectópicos, implantes esses que geralmente ocorrem na região da pelve, mas também 
são observados no abdome superior, pulmões, diafragma, bexiga, rins e intestinos. Os locais mais comuns onde se observa focos de endometriose são os ovários, trompas de falópio, cólon sigmoide e apêndice. Quando isso acontece, ocorre processo inflamatório, causando a dor crônica sentida pela grande maioria das mulheres e pode bloquear as trompas de falópio gerando infertilidade na mulher. Como o crescimento dos implantes depende de esteroides produzidos pelos ovários, é uma doença que afeta mais gravemente mulheres de 25 a 35 anos. Os sintomas estão associados ao período menstrual e sobretudo por ação hormonal que geralmente são investigados após queixas de dores pélvicas. Pacientes podem apresentar uma ampla gama de sintomas, entretanto o sintoma mais relatado pelas mulheres é a Dor Pélvica Crônica (DPC) (HARRIS et al., 2018; CACCIATORI; MEDEIROS, 2015; BAUMART, 2015). A Figura 1 mostra onde os focos de endometriose podem se instalar no sistema genital feminino.

Figura 1 - Sistema genital feminino e os locais com focos de endometriose

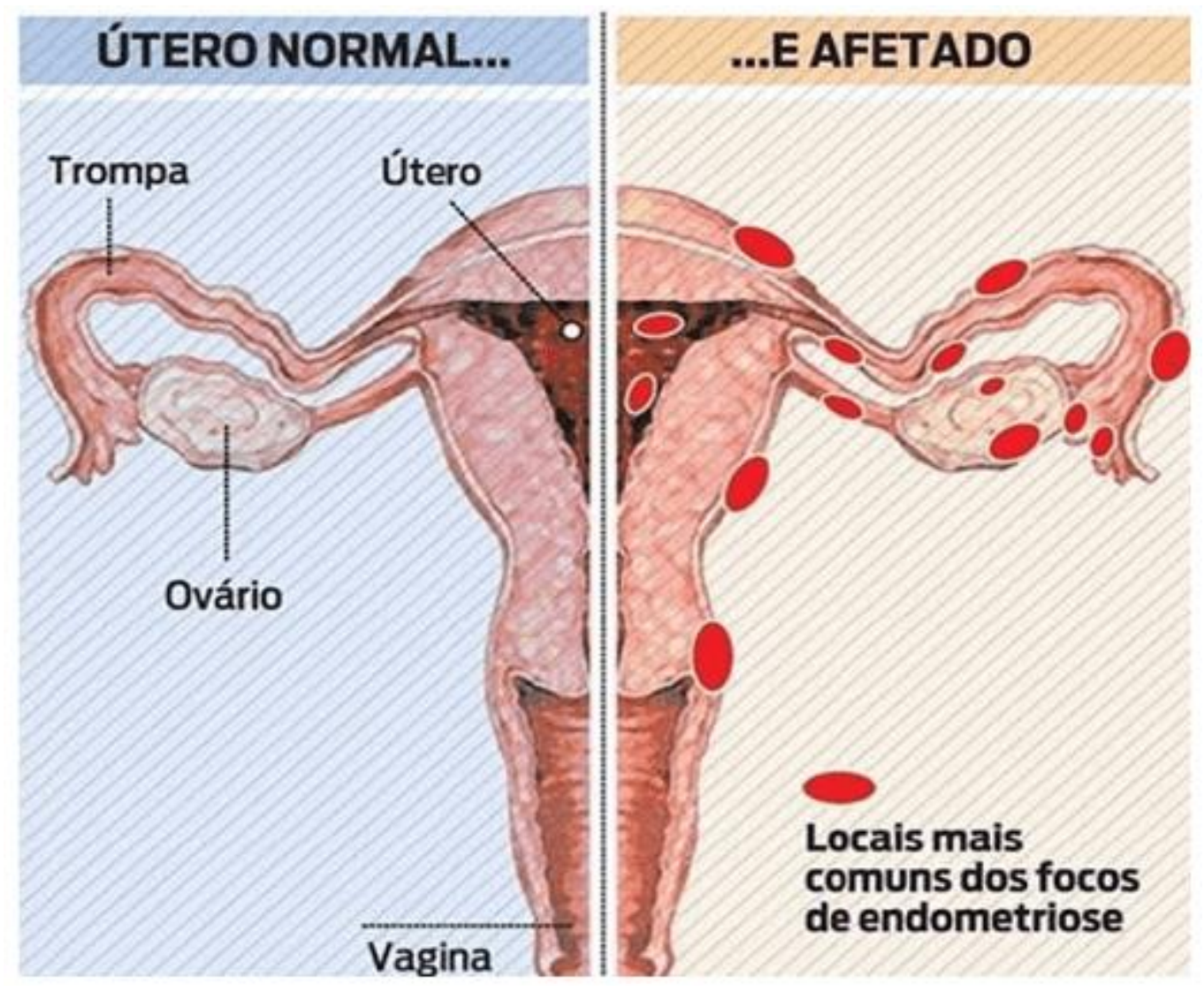


Fonte: Hospital das Clínicas de Botucatu - Unesp

Em estudo feito por Shen et al. (2015), a endometriose também está significativamente associada a concentrações séricas elevadas de biomarcadores importantes como glicoproteínas antígeno de câncer (CA-125), antígeno carboidrato (CA19-9), zinco-alfa-2-glicoproteina, glicodelina- A, além de marcadores imunológicos e citocinas inflamatórias como proteína C reativa (PCR), interleucina-4 (IL-4), interleucina-8 (IL-8), fator de necrose tumoral- alfa (TNF- $\alpha$ ). Entretanto o biomarcador mais utilizado para compor a investigação não invasiva de endometriose é o CA-125 pois nos estágios mais avançados da doença encontra-se ainda mais aumentado.

O CA-125 é uma glicoproteína com alto carboidrato como seu componente, essa glicoproteína é produzida no período fetal por tecidos epiteliais e na idade adulta, pode ocorrer no epitélio normal das trompas de falópio, tubos e colo do útero (FIALA et al., 2018).

Por existir várias formas de endometriose desde poucos implantes no peritônio pélvico a extensa aderência e infiltrações de órgãos fora da pélvis, a doença pode ser classificada por um dos sistemas de classificação mais utilizados atualmente que é a American Society for Reproductive Medicine (ASRM) e também conforme com o Protocolo Clínico e Diretrizes Terapêuticas - Endometriose (PCDT), publicado pelo Ministério da Saúde a classificação ASRM é um sistema de pontuação baseado na aparência, tamanho dos implantes e extensão das aderências. O escore define quatro estágios: estágio I (endometriose mínima) em que o foco da endometriose é isolado, sem adesão óbvia; estágio II (endometriose leve) , apresentam lesões livres e lesões dispersas onde os implantes são de características superficiais; estágio III (endometriose moderada) onde apresenta diversos implantes com aderências de implantes superficiais e profundos; estágio IV (endometriose grave) é percebido muitos implantes tanto superficiais quanto profundos, apresentando membranas densas e aderentes além da presença de cistos grandes chamados endometriomas. Apesar da classificação da ASRM ser amplamente utilizada e aceita em todo o mundo e sobretudo de fácil classificação e principalmente fácil de ser compreendida pelos pacientes, ela apresenta algumas limitações como não relacionar 
- grau de gravidade da doença com a dor. Algumas pacientes que seriam classificadas como "graves" pelos gráficos revisados do ASRM sentem pouca dor, e apresentam infertilidade, outras com apenas lesões superficiais e pequenas aderências, experimentam dor intensa. Embora existam muitas teorias quanto ao surgimento e desenvolvimento da patologia, o fluxo menstrual retrógrado através das trompas de falópio onde células progenitoras epiteliais derivadas do escoamento de tecido endometrial podem implantar no peritônio, ovários ou na bolsa reto vaginal é a mais referida. Uma vez estabelecidos, esses hormônios responsáveis pelas lesões endometriais ativas, conduzem reações agudas e crônicas que levam a aderências pélvicas provocando dor e infertilidade. A menstruação está associada a um acréscimo da concentração de glóbulos vermelhos e brancos no liquido peritoneal. Episódios repetidos de hemorragia ocorrem na endometriose no início da menstruação, a hemoglobina extracelular, o heme e os derivados do ferro na endometriose causam danos ao ácido desoxirribonucleico (DNA, sigla em inglês) e mutações, que criam suscetibilidade celular aumentada à morte celular mediada por oxidantes. O excesso de danos no DNA e mutações estão ligados à morte celular, mas não à carcinogênese. A endometriose está associada a dor pélvica crônica, em algumas situações pode causar infertilidade feminina e, raramente, transformação maligna. A Suscetibilidade individual a endometriose, entretanto, é influenciada por fatores genéticos, fatores clínicos, endócrinos e ambientais (CANIS et al., 1997 apud TANBO; FEDORCSAK, 2016; BRASIL, 2016; KOBAYASHI, 2016 ANDRES et al., 2018).

É uma patologia de alto impacto em mulheres na idade reprodutiva, resultando como consequências uma má qualidade de vida, desconforto, além de problemas mentais, físicos, conjugais e sociais (RODRIGUES et al., 2015).

\subsection{DOR PÉLVICA CRÔNICA}

É uma condição que pode ocorrer em conjunto à endometriose, com prevalência de 1 a $60 \%$ entre as mulheres. A condição de dor pélvica presente por mais de 6 meses é definida como dor pélvica crônica. Os sintomas incluem dor na região pélvica, 
formigamento, sensação de queimação, distúrbios da micção, bexiga hiperativa (incluindo frequência e urgência), dor na micção (KUHN, 2019).

A DPC possui uma infinidade de causas, e sobretudo produz complicações médicas complexas e desafios de saúde mental para milhões de mulheres, o seu impacto nas famílias, na convivência em sociedade para as que sofrem dessa condição é imenso, pois essas mulheres lutam para manter uma qualidade de vida enquanto gerenciam suas condições. Essa complexidade da DPC feminina atrasa e impede o diagnóstico correto, o tempo desde a queixa inicial até o diagnóstico final para mulheres com DPC e endometriose dura em média de 6 a 8 anos mesmo a origem da DPC sendo comum nas mulheres com essa patologia. Atrasos e diagnósticos incorretos podem levar a uma significativa frustração e desconfiança do paciente para com o seu médico. Infelizmente, esses atrasos também podem permitir a progressão significativa da doença (HARKINS, 2018).

As terapias médicas para minimizar os episódios de dor incluem anticoncepcionais orais combinados, progestógenos e agonistas do hormônio liberador de gonadotropina $(\mathrm{GnRH})$, bem como andrógenos e tratamentos não hormonais, como analgésicos e agentes anti-inflamatórios não esteroides (AINEs). Os tratamentos hormonais para endometriose focam no cessamento das variações hormonais (gonadotrofina e hormônios ovarianos), tendo como resultado a inibição da ovulação e menstruação, portanto a atenuação da inflamação. O tratamento hormonal por si só não fornece controle da doença a longo prazo, porque muitas vezes é interrompido devido a quantidade significativa de efeitos colaterais indesejáveis (MILLOCHAU et al., 2016).

A intervenção cirúrgica por videolaparoscopia é o tratamento mais vantajoso para melhora da DPC quando comparado com recurso medicamentoso. Quando todas as lesões ectópicas são removidas há uma melhora significativa da dor e qualidade de vida das mulheres (BISHOP, 2017).

Além da dor pélvica crônica, muitas mulheres sofrem também com a Síndrome da Fadiga Crônica (SFC) que é uma síndrome caracterizada por uma fadiga prolongada 
associada a sintomas físicos como: dores de cabeça, dores musculares e articulares, alterações no sono, e quando associado a alguma atividade física de grande esforço ocorre uma piora nesses sintomas. A SFC não traz apenas fadiga física, mas também causa sobretudo uma fadiga mental para essas pacientes com endometriose gerando dificuldades para concentração e problemas de memória (BJØRKLUND et al., 2019).

Segundo Faro et al. (2016), o maior impacto da fadiga crônica está entre as mulheres quando comparado ao público masculino. Isso se dá por uma possível causa hormonal onde o estrogênio (hormônio responsável pelo controle da ovulação feminina) e os receptores de estrogênio, especialmente o receptor de estrogênio beta (RE- $\beta$ ) que é prejudicado e pouco expresso em pacientes com SFC, que é especialmente propenso a piorar no sexo feminino (DE KORWIN et al., 2016).

A fadiga é um sintoma desprezado na endometriose, apesar de afetar a maioria das mulheres. Porém não é amplamente discutido na literatura. É um sintoma que também causa grande sofrimento, impactando de forma negativa nas atividades diárias e no conforto de mulheres afetadas com a endometriose. Além disso, a inflamação causada por lesões de endometriose e o estímulo do sistema imunológico podem estar envolvidos na presença de fadiga crônica. No entanto, poucos estudos com grandes tamanhos de amostra investigaram a fadiga como um sintoma de endometriose. Um estudo de caso-controle que ocorreu em hospitais e consultórios particulares na Suíça, Alemanha e Áustria entre os anos de 2010 e 2016 onde 1120 mulheres com e sem endometriose foram avaliadas, os resultados do estudo mostrou que a fadiga frequente estavam presentes em $50,7 \%$ em mulheres com diagnóstico de endometriose contra $22,4 \%$ de mulheres sem endometriose, Para melhora da qualidade de vida dessas mulheres, a fadiga crônica deve, além da dor pélvica crônica, ser tratada como parte da rotina de cuidados e tratamentos médicos, juntamente com tratamento padrão de endometriose (RAMIN-WRIGHT et al., 2018).

\subsection{DIETOTERAPIA E ENDOMETRIOSE}

A identificação de alimentos que possuam certa relação com endometriose e mudanças no padrão da dieta que podem trazer benefícios juntamente ao empenho 
de alcançar os objetivos da terapia no sentido de diminuir o avanço da doença a níveis mais graves, prevenir possíveis focos da doença após tratamento cirúrgico, diminuir sintomas de dor e reestabelecer a qualidade de vida causa um grande interesse entre as mulheres. A intervenção nutricional pode ser compreendida como um tratamento alternativo e adjuvante da doença uma vez que a mulher pode incluir novos hábitos alimentares e comportamentais à sua rotina diária (PODGAEC, 2015).

A dieta é um dos principais fatores de risco para muitas doenças crônicas. A ligação entre dieta e endometriose, ressalta a competência de componentes anti-inflamatórios presentes nos alimentos minimizar sintomas ligados a doença. O papel da dieta na endometriose ganhou um olhar mais crítico nos últimos anos, em virtude de que os hábitos alimentares podem afetar vários processos que estão envolvidos na endometriose, incluindo inflamação, metabolismo de prostaglandinas e atividade estrogênica (SAGUYOD, 2018).

Uma dieta saudável e equilibrada pode ter um impacto favorável nos sintomas, onde recomenda-se evitar o consumo de bebidas alcoólicas, bebidas estimulantes como a cafeína, alimentos ricos em gorduras saturadas e gorduras trans além da diminuição também no consumo de carne vermelha. Um dos possíveis fatores patogênicos que afetam a endometriose e a dismenorreia são os níveis de prostaglandinas. Os ácidos graxos ômega- 6 derivados da dieta são os precursores das prostaglandinas próinflamatórias: prostaglandinas-E2 (PGE2) e prostaglandinas-F2 alfa (PGF2 $\alpha$ ) que provavelmente aumentam as cólicas uterinas e causam sintomas físicos dolorosos. Entretanto, as prostaglandinas-E3 (PGE3) e prostaglandinas-E3 alfa (PGE3 $\alpha$ ) derivadas dos ácidos graxos ômega-3, estão associadas à redução da inflamação e, consequentemente, menos dor (JURKIEWICZ-PRZONDZIONO et al., 2017).

Ainda embora não haja um acordo científico sobre os métodos dietéticos a serem seguidos pelas pacientes é absolutamente importante uma orientação nutricional baseada em evidências cientificas relatadas em estudos específicos e sólidos associados ao conhecimento dos nutrientes e as funções dos alimentos no organismo fazendo uma ponte também entre a experiência humana e clínica. Mulheres com endometriose devem ser sensibilizadas sobre como um plano alimentar equilibrado, 
variado e sobretudo adaptado à sua doença pode ter resultados satisfatórios em todo o processo. Em relação aos suplementos nutricionais, os mesmos deverão ser definidos e prescritos em concordância com cada caso levando sempre em consideração o quadro clínico e história alimentar da paciente (PODGAEC, 2015).

De um modo geral, a recomendação é que as pacientes com endometriose se adequem a uma dieta saudável onde haja o predomínio de alimentos frescos e não processados. (AGUILAR-AGUILAR, 2020).

A endometriose é uma doença que depende de estrogênio, com isso a diminuição das lesões no endométrio pode ser dar de forma farmacológica, por processo cirúrgico, após a menopausa, ou sob influência da alimentação com uma dieta a base de alimentos e suplementos dietéticos que reduzam os níveis do hormônio estrogênio sendo possível atingir com sucesso o tratamento (KODAMAN, 2015; AMARAL et al., 2017).

O estrogênio e a exposição ao estrogênio desempenham um papel crucial na evolução da doença através dos receptores de estrogênio (REs) que também incluem receptor de estrogênio- alfa (RE- $\alpha$ ) e receptor de estrogênio-beta (RE- $\beta$ ). O estradiol (E2) que é a forma mais ativa do estrogênio natural do corpo, é um hormônio fundamental para o crescimento e persistência do tecido endometrial, bem como a inflamação e a dor associadas a ele. O E2 atinge o endométrio pela circulação sanguínea, e o acúmulo local desse hormônio tem sido considerado um papel significante no desenvolvimento e progressão das lesões de endometriose por ligação e ativação de REs. Este processo como é mostrado na Figura 2 é regulado positivamente em tecido endometrial, alterando as atividades das enzimas envolvidas na biossíntese e inativação do E2. Na verdade, os tecidos endometriais possuem a capacidade de sintetizar novamente E2 a partir do colesterol, já que existe uma alta expressão de duas enzimas importantes envolvidas no processo de biossíntese de estrogênio: aromatase (CYP19A1) (enzima que catalisa a conversão da testosterona em estradiol) e proteína reguladora aguda esteroidogênica (StAR). Um endométrio normal não tem capacidade para sintetizar estrogênio devido à ausência dessas enzimas (TANG et al., 2019). 
Figura 2 - Papel do estrogênio e receptores de estrogênio no endométrio normal e lesões de endometriose.

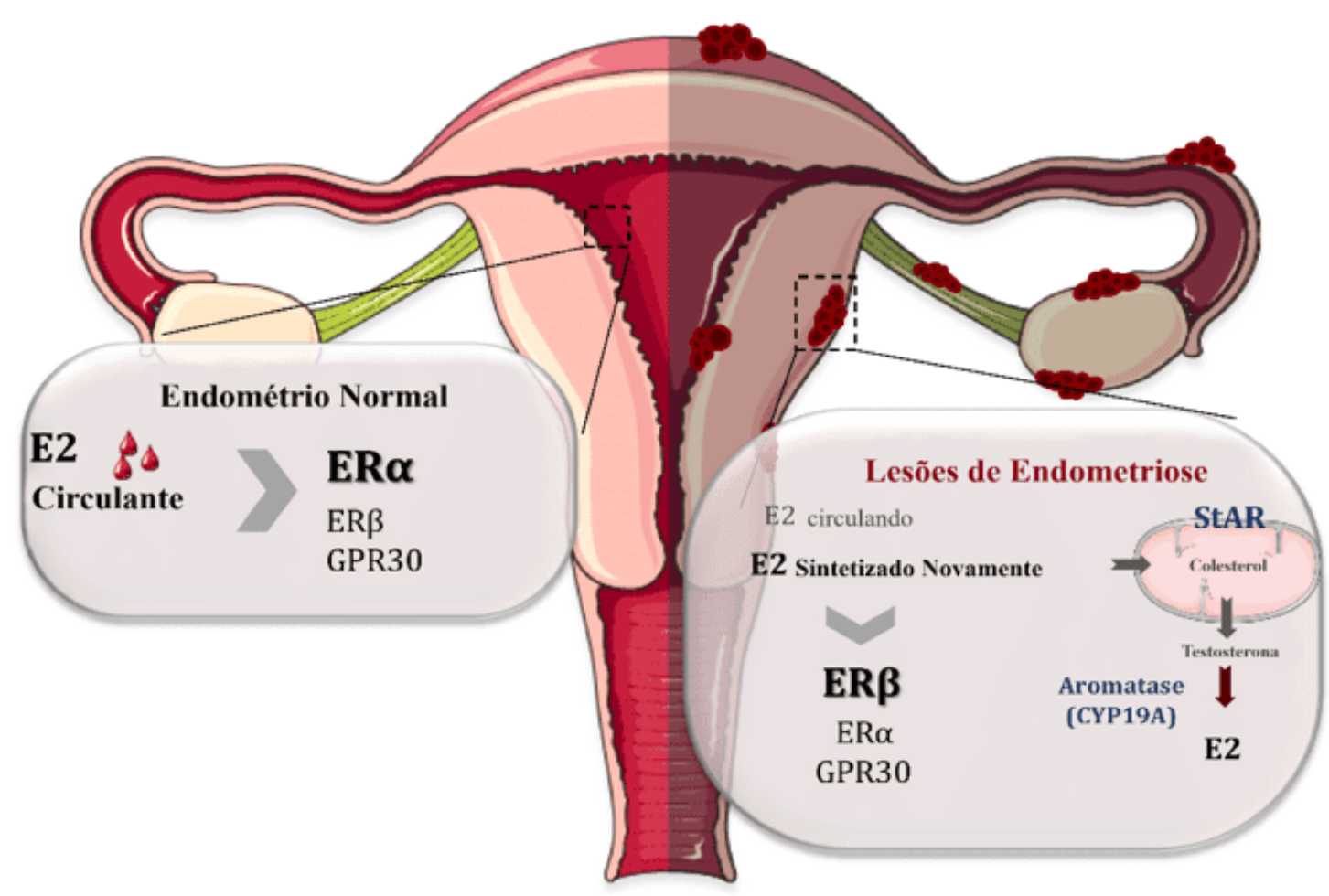

Fonte: Figura adaptada de Chantalat at al. 2020

\subsection{INGESTÃO DE GORDURAS E ENDOMETRIOSE}

As gorduras são benéficas para o metabolismo do corpo além de ajudar na absorção de vitaminas e sintetizar energia para que o corpo humano execute suas funções. São classificadas como ácidos graxos insaturados divididos em monoinsaturados e poliinsaturados além de gorduras saturadas e trans (BOTHAM; MAYES, 2017). O Quadro 1 exemplifica alguns alimentos fontes dessas gorduras.

Quadro 1 - Classificação dos ácidos graxos e suas fontes alimentares

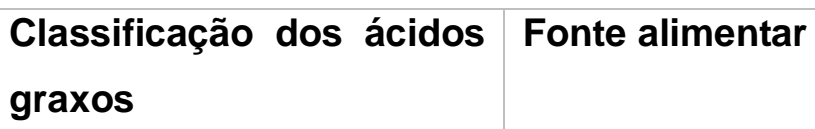

Quantidade de ácidos graxos em $100 \mathrm{~g}$ de fonte alimentar 


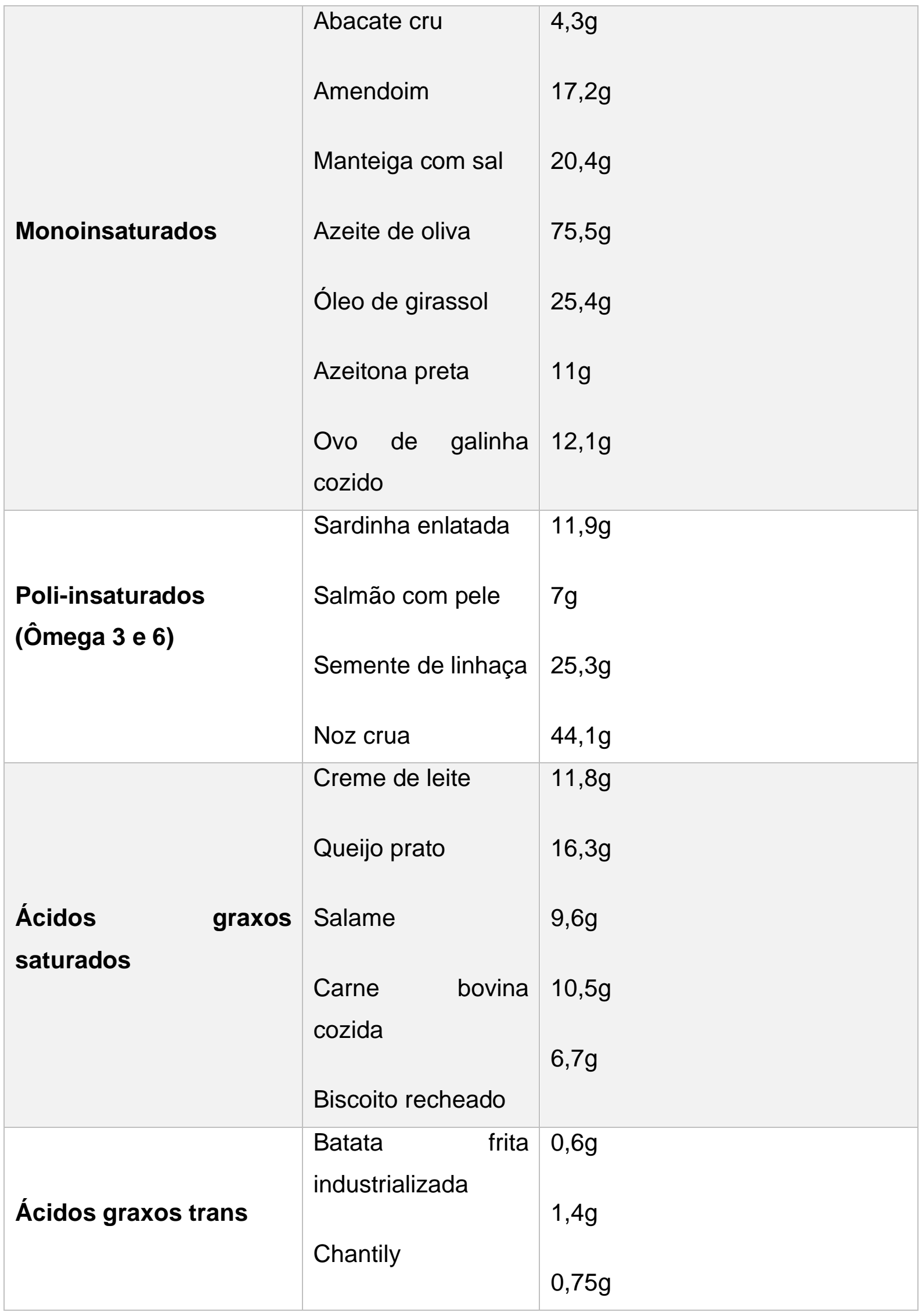




Mistura pão de
queijo

Fonte: Tabela Brasileira de Composição de Alimentos - Universidade Estadual de Campinas - Unicamp (TACO). 2011 Tabela Brasileira de Composição dos Alimentos - Universidade de São Paulo - USP (TBCA). 2020

Diversos alimentos e compostos como nozes, sementes oleaginosas, produtos de soja, cereais, pães, produtos cárneos, e alimentos processados que podem conter traços de soja estão relacionados à liberação de estrogênio, as gorduras também são um exemplo desses compostos, quando são ingeridos, os ácidos graxos através de processos metabólicos, sofrem transformações em novos ácidos graxos, e é por essa conversão que são produzidas as respostas inflamatórias da doença relacionando com quadro clínico de dor (CAMBIAGHI; DE SOUZA ROSA, 2016; CARDENAS-TROWERS et al., 2018).

Em um estudo relacionando endometriose a uma dieta rica em gorduras feito por Heard et al. (2016) usando modelos de camundongos com a doença induzida, a promoção da endometriose por uma exposição a dieta com alto teor de gorduras (45\% de calorias de gordura na dieta dos camundongos) foi avaliada. A confirmação de mudanças de expressão gênica para genes associado à inflamação ou estresse oxidativo de lesões foi realizado por PCR onde a interleucina-17 (IL-17A) apresentou um valor de 4,5 para dieta rica em gordura e 1,0 para dieta controle. Os valores de fator de necrose tumoral alfa (TNF- $\alpha$ ) para dieta rica em gordura foi de $45.5 \mathrm{pg} / \mathrm{ml}$ em comparação a dieta controle $33.1 \mathrm{pg} / \mathrm{ml}$ (picograma por mililitro). Conforme os resultados obtidos por uma dieta rica em gorduras aumentou a inflamação dento do peritônio pelas citocinas inflamatórias TNF-a e IL-17A levando a uma inflamação sistêmica e estresse oxidativo, ambas características de mulheres com endometriose.

Através de estudo realizado por Oteng e kersten (2020) com células cultivadas, as gorduras trans estimularam o estresse oxidativo e o processo de inflamação através das espécies reativas de oxigênio (EROs). Além de impactar na inflamação e nas vias associadas ao estresse, os ácidos graxos trans têm uma profunda influência no metabolismo lipídico. 
Os ácidos graxos trans saturados ou saturados também estão relacionados a uma amplificação do risco de desenvolver endometriose. Uma outra forte ligação entre endometriose e níveis de estrogênio, é o consumo de soja que também parece estar associada a um perigo de desenvolver endometriose (JURKIEWICZ-PRZONDZIONO et al., 2017).

Nos hábitos alimentares atuais, a gordura saturada e a gordura trans são consumidas com mais frequência. Ressalta-se também que o consumo de gorduras na dieta ocidental é maior, como o ácido linoleico, que se torna o ômega 6 após ser metabolizado, enquanto a ingestão de gordura formada pelo ácido linolênico ou ômega 3 é menor (GARCIA, 2018).

Em todo o mundo, o predomínio de doenças crônicas é alto e insustentável para a maioria dos sistemas de saúde. Embora a causa seja complexa, muitas doenças crônicas podem ser evitadas ou reduzir seus efeitos por meio de práticas ao longo da vida como por exemplo uma adesão à dieta saudável (NEUHOUSER, 2019).

De acordo com o Guia Alimentar para a População Brasileira, uma alimentação saudável deve ser adquirida baseada a partir de alimentos in natura ou minimamente processados onde haja predominância dos alimentos de origem vegetal (BRASIL, 2014).

Já o relatório americano Dietary Guidelines for Americans 2015-2020, também descreve um padrão alimentar saudável como aquele que inclui uma variedade de vegetais de todos os subgrupos, frutas, grãos, laticínios sem gordura ou com baixo teor de gordura. O relatório especifica ainda que um padrão alimentar saudável limita a gordura saturada, a gordura trans, os açúcares adicionados e o sódio.

Podgaec et al. $(2015,2018)$ afirma que por ser uma doença crônica, o sistema imunológico está também relacionado com a fisiopatologia da endometriose, portanto, incluir na dieta compostos alimentícios ricos em antioxidantes e nutrientes fitoquímicos podem facilitar a reduzir a condição inflamatória da doença e progressão da mesma. Compreendendo que os nutrientes estão envolvidos na produção e função de várias 
células imunológicas do organismo é de suma importância identificar ausência ou excesso desses componentes químicos para obter uma função imune adequada e suficiente em portadoras de endometriose, a falta afeta seriamente as respostas inatas e adaptativas do sistema pois os macros e micronutrientes possuem efeito sinérgico favorecendo a homeostase do corpo.

\subsection{INGESTÃO DE ÔMEGA 3 E 6: FATORES INFLAMATÓRIOS DA ENDOMETRIOSE}

Os ácidos graxos representam dois diferentes tipos de ácidos graxos poli-insaturados, o ômega-6 (ácido linoleico e ácido araquidônico) e o ômega-3 (ácido alfa-linolênico, ácido eicosapentaenoico EPA e ácido docosaexaenoico DHA). Eles podem ser encontrados em diferentes concentrações no mesmo alimento, entretanto a quantidade consumida na dieta precisa ser controlada, aumentando assim o consumo de ômega 3 e reduzindo o consumo de ômega 6 (BENJAMIM et al., 2019).

Segundo a Organização Mundial da Saúde (OMS) e a Organização das Nações Unidas para Agricultura e Alimentação (FAO, sigla em inglês), a recomendação da proporção de consumo desses ácidos graxos é dada pela razão ômega-6:ômega-3 de 5:1 podendo chegar até 10:1, no entanto, existe diferença na razão desta recomendação nos países ocidentais, que pode variar de 30:1 ou até mesmo 50:1. Isso se deve ao alto consumo de produtos industrializados ricos em ácidos graxos ômega-6, essenciais para o organismo, porém quando em concentrações desproporcionais tende a produzir inflamação crônica no indivíduo (CHRIST et al., 2019; PEREIRA et al., 2019).

Em estudo recente realizado por De Arruda Costa et al. (2018) investigou-se através de uma revisão de literatura que um padrão alimentar rico em ômega-3 pode ser utilizado como tratamento auxiliar para reduzir as aderências endometriais e consequentemente redução de episódios de inflamação e dor. Além de poder reduzir os sintomas comuns em mulheres com endometriose como por exemplo transtorno de ansiedade e depressão. 
Estudos descobriram uma ligação entre o consumo de ácidos graxos ômega-3 e uma possível melhora em sintomas ligados à endometriose como diminuição dos níveis de IL-6 (interleucina-6), TNF- a (fator de necrose tumoral alfa) e VEGF (fator de crescimento endotelial) , especialmente em estudos experimentais com animais como o estudo de Akyol et al. (2016) em modelo experimental prospectivo, simples-cego, randomizado e controlado realizado em 30 ratas com implantes endometrióticos induzidos cirurgicamente por implante de tecido entrometiótico no peritônio abdominal onde o uso de ômega-3 indicou uma regressão significativa, tanto em tamanho quanto em padrões histológicos dos implantes endometrióticos. Os ratos do grupo ômega-3 receberam $450 \mathrm{mg} / \mathrm{kg} / \mathrm{d}$ (miligramas por quilo por dia) e o grupo controle não recebeu nenhuma quantidade de ômega-3. Após 4 semanas de avaliação os autores alcançaram os resultados mostrados na Tabela 1.

Tabela 1. Valores de pré e pós-tratamento com ômega-3 após 4 semanas

\begin{tabular}{|c|c|c|c|}
\hline $\begin{array}{l}\text { Citocinas } \\
\text { inflamatórias }\end{array}$ & $\begin{array}{l}\text { Período do } \\
\text { tratamento }\end{array}$ & Grupo ômega-3 & Grupo controle \\
\hline \multirow[t]{2}{*}{ IL-6 (pg/ml) } & \multirow{2}{*}{$\begin{array}{l}\text { Pré-tratamento } \\
\text { Pós-tratamento }\end{array}$} & 70,7 & 67,3 \\
\hline & & 63,1 & 62,2 \\
\hline \multirow[t]{2}{*}{ TNF- $\alpha(\mathrm{pg} / \mathrm{ml})$} & \multirow{2}{*}{$\begin{array}{l}\text { Pré-tratamento } \\
\text { Pós-tratamento }\end{array}$} & 15,4 & 19,9 \\
\hline & & 10,5 & 18,5 \\
\hline \multirow[t]{2}{*}{ VEGF (pg/ml) } & \multirow{2}{*}{$\begin{array}{l}\text { Pré tratamento } \\
\text { Pós tratamento }\end{array}$} & 19,3 & 17,4 \\
\hline & & 13,7 & 16,4 \\
\hline
\end{tabular}

Fonte: Tabela adaptada de Akyol et al. 2016 IL-6 (Interleucina-6), TNF- a (Fator de necrose tumoral alfa), VEGF (Fator de Crescimento Endotelial) pg/mI (picograma por mililitro)

Em um outro estudo controlado feito por Nodler et al. (2020), onde 147 mulheres em idades variadas com endometriose confirmada cirurgicamente e com presença de dor pélvica foram suplementadas com $720 \mathrm{mg}$ (miligramas) de óleo de peixe (rico em ômega-3) diariamente por um espaço de tempo de 6 meses tendo como resultado 
através da pontuação da escala visual analógica (EVA) 5,9 antes da suplementação e 5,2 após suplementação de óleo de peixe depois de 6 meses. Os resultados não foram drasticamente significativos, entretanto observou-se uma tendência à melhoria da dor pélvica nas pacientes.

O ômega-3 e 6 em contexto equilibrado desempenha um papel vital no controle da dor, sintoma super comum nas pacientes com endometriose o que é benéfico para redução da inflamação devido às suas moléculas anti-inflamatórias. Embora os efeitos anti-inflamatórios tenham sido observados em um consumo maior de ômega-3 na dieta, o mecanismo pelo qual esse ácido graxo atua na resposta imunológica é pouco conhecido. Ele também pode reduzir a síntese do TNF- $\alpha$ e interleucinas responsáveis pela resposta inflamatória da doença, além de ser precursor de mediadores lipídicos chamados de protectinas e resolvinas, que possuem características anti-inflamatórias e imunomoduladoras. Em estudo feito para analisar as associações entre a razão de ácidos graxos ômega- 6 e ômega-3 na dieta, a ingestão de gorduras foi estimada por meio do Recordatório de 24 Horas, foram considerados os registros alimentares de 3.303 indivíduos, com idade igual ou maior que 10 anos. Os resultados mostraram valores mais baixos da relação ômega-6:ômega-3 em adultos e idosos. A prevalência de ômega-3 inadequado na dieta atingiu 13\% da população, e o ômega 6 chegou a $100 \%$ nas mulheres adultas, e com isso percebe-se que os grupos mais vulneráveis são os adolescentes e aqueles que não ingerem diariamente nutrientes benéficos para saúde além naqueles que não fazem nenhuma atividade física. O efeito de inibir e/ou estimular a resposta imunológica causado pelo ômega- 6 dependerá do seu equilíbrio em relação ao ômega-3 (PORFÍRIO et al., 2017; GHEDINI; SIMONIAN, 2017).

\subsection{ANTIOXIDANTES E ENDOMETRIOSE}

Estudos recentes têm colocado a atenção sobre o papel do estresse oxidativo na endometriose, definindo como uma oscilação entre espécies reativas de oxigênio (EROs) e antioxidantes, que pode estar envolvido no desenvolvimento da endometriose gerando uma reação inflamatória abrangente na cavidade peritoneal. As espécies reativas de oxigênio são mediadas e produzidas pelo metabolismo normal 
do oxigênio e são mediadores inflamatórios conhecidos por modular a multiplicação celular e ter efeitos deletérios sobre o organismo (SCUTIERO et al., 2017).

Em indivíduos saudáveis, EROs e antioxidantes estão em equilíbrio, mas quando o equilíbrio se inclina para uma superabundância de EROs, ocorre o estresse oxidativo e pode afetar toda a vida reprodutiva de uma mulher e isso pode acontecer devido a uma inadequação da proteção antioxidante ou excesso de produção de EROs (DONNEZ et al., 2016).

A liberação demasiada de espécies reativas de oxigênio não só causa danos às células, mas também altera a função celular ao regular a atividade de proteína, lipídica e a expressão genética, além de desempenhar um comportamento relevante na regulação do fator de transcrição nuclear kappa B (NF-kB), que atua na resposta imune e regula a expressão de genes essenciais durante a inflamação, e por esse motivo está envolvido na endometriose (SAMIMI et al., 2019).

Nas células endometriais, a produção de EROs relacionada ao processo de proliferação é aumentada, onde espécies reativas de oxigênio e os radicais livres auxiliam no crescimento e adesão dessas células mostrados na Figura 3. Em circunstâncias normais, as células imunes seriam capazes de eliminar as células derivadas do endométrio, evitando assim sua instalação na cavidade peritoneal. Quando todo esse processo sofre uma falha o surgimento da doença e seus sintomas se instalam (VITALE et al., 2018). 
Figura 3- Produção de EROs, adesão e proliferação no tecido endometrial em locais ectópicos

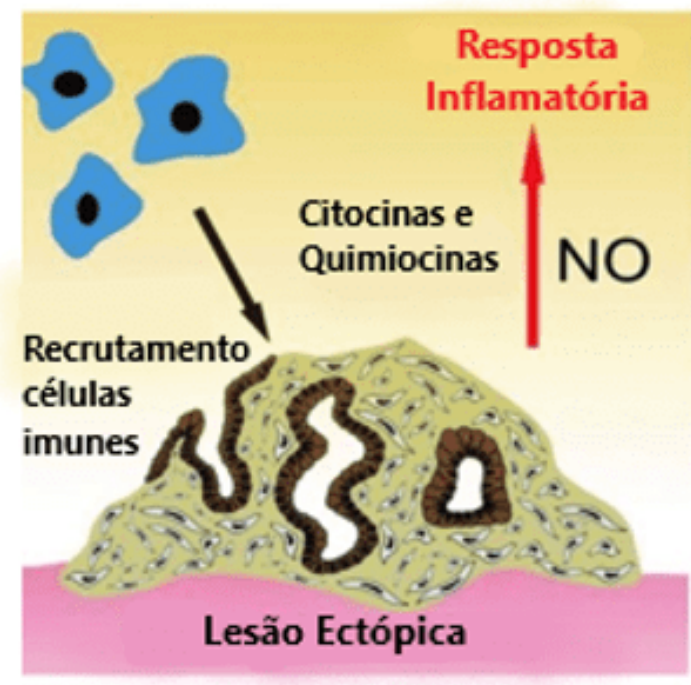

Fonte: Figura adaptada de Hill et al., 2020.

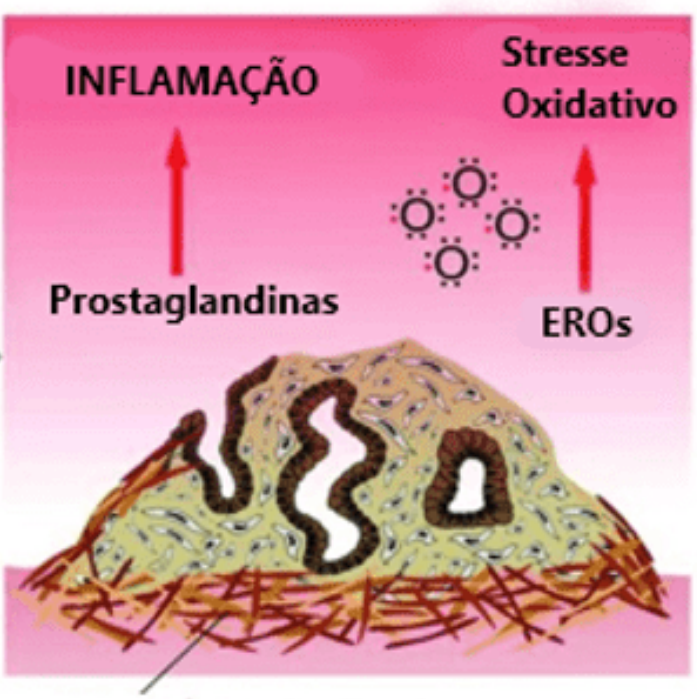

Fibrose e adesão

De acordo com estudo transversal de Nasiri et al. (2017) o aumento dos marcadores de estresse oxidativo e a diminuição dos níveis de antioxidantes no fluido folicular de mulheres com endometriose foram confirmados em comparação ao grupo controle, especificamente o grupo endometriose, as concentrações de espécies reativas de oxigênio, óxido nítrico e peroxidação lipídica no liquido peritoneal e no sangue foram aumentadas o que certamente promove aderência celular e ativação dos macrófagos que por vez liberam EROs e nitrogênio propagando o estresse oxidativo. Um dos principais fatores ambientais em que o ser humano está exposto todos os dias é a alimentação. A qualidade, quantidade e principalmente o tipo de alimento que é ingerido possuem uma grande importância, e isso se dá não somente pelo valor nutricional que um alimento saudável oferece ao organismo, mas também pela aptidão que esses nutrientes e sobre tudo os seus compostos bioativos participam de uma forma inteligente com o corpo (SOARES et al., 2015).

Uma dieta com elevados componentes antioxidante e anti-inflamatórios pode ser alcançada para tratamento complementar da endometriose e seus sintomas, incluindo na rotina determinados alimentos com propriedades funcionais para promover uma 
melhor bem-estar na vida de mulheres com essa patologia (BOVE; DE SOUZA, 2019). No Quadro 2 é possível observar alguns alimentos com propriedades funcionais.

Quadro 2 - Alimentos e suas propriedades funcionais

\begin{tabular}{|l|l|}
\hline Alimentos & Propriedades funcionais \\
\hline $\begin{array}{l}\text { Sardinha, Salmão, Atum, } \\
\text { Anchova }\end{array}$ & $\begin{array}{l}\text { Rico em ômega-3, possui ação anti-inflamatória e } \\
\text { auxilia na redução do colesterol LDL }\end{array}$ \\
\hline $\begin{array}{l}\text { Óleos vegetais (azeite de oliva, } \\
\text { óleo de linhaça, óleo de } \\
\text { algodão) }\end{array}$ & $\begin{array}{l}\text { Rico em ômega-6, estimula o sistema imunológico, } \\
\text { também possui ação anti-inflamatória, seu consumo } \\
\text { adequado reduz risco de doença cardiovascular }\end{array}$ \\
\hline $\begin{array}{l}\text { Chá verde, amoras, framboesa, } \\
\text { uva roxa, mirtilo, vinho tinto }\end{array}$ & $\begin{array}{l}\text { Possuem como componente bioativo as catequinas e } \\
\text { resveratrol que tem ação antioxidante, reduzem } \\
\text { colesterol, estimulam sistema imunológico e podem } \\
\text { prevenir alguns tipos de câncer }\end{array}$ \\
\hline $\begin{array}{l}\text { Tomate, goiaba, pimentão } \\
\text { vermelho, molho de tomate e } \\
\text { frutas } \\
\text { (carotenoides) }\end{array}$ & $\begin{array}{l}\text { Licopenos com funções antioxidantes que auxiliam na } \\
\text { proteção celular contra os radicais livres, auxilia } \\
\text { redução de colesterol e tem ação preventiva contra } \\
\text { alguns tipos de câncer, principalmente o de próstata }\end{array}$ \\
\hline $\begin{array}{l}\text { logurtes, produtos lácteos } \\
\text { fermentados }\end{array}$ & $\begin{array}{l}\text { Probióticos que auxiliam no equilíbrio da microbiota } \\
\text { intestinal através das bifidobactérias e dos lactobacilos } \\
\text { preservando o bom funcionamento da função intestinal }\end{array}$ \\
\hline $\begin{array}{l}\text { Frutas, grãos } \\
\text { tubérculos, vegetais }\end{array}$ & $\begin{array}{l}\text { Ricos em fibra são ótimas opções de prebióticos que } \\
\text { auxiliam na função intestinal, promove saciedade e } \\
\text { redução de colesterol }\end{array}$ \\
\hline Ricas em betacaroteno tem ação hipotensiva auxiliando \\
na redução da pressão arterial, antioxidantes, auxilia na \\
saúde ocular
\end{tabular}

Fonte: Sociedade Brasileira de Alimentação e Nutrição - SBAN; Henrique et al. 2018. 


\subsection{VITAMINA C, D, E COMO TRATAMENTO ADJUVANTE NA ENDOMETRIOSE}

\subsubsection{VITAMINA C}

A vitamina C (ácido ascórbico) é um micronutriente essencial para o ser humano. É um potente antioxidante que contribui para a defesa imunológica, participando de várias funções celulares do sistema imunológico inato e adaptativo. Esse micronutriente tem um papel muito mais importante do que somente ser uma vitamina anti-escorbuto (doença causada pela deficiência de vitamina $\mathrm{C}$ ). Além de desempenhar um papel na prevenção de invasão e metástase, é um antioxidante que possui eficácia anti-inflamatórias e angiogênicas. A vitamina $C$ limita diretamente a secreção de citocinas pela função de eliminação de radicais livres, ela também impede a secreção de citocinas indiretamente por meio da supressão intracelular de NF-kB (CARR; MAGGINI, 2017; ERTEN et al., 2016).

De acordo com o Institute of Medicine os valores recomendados para o consumo de vitamina C por dia para mulheres adultas a partir de 19 anos é de $75 \mathrm{mg} / \mathrm{d}$ (miligramas por dia).

Um estudo desenvolvido por Erten et al. (2016) de característica prospectiva, comparativa e experimental onde animais foram divididos em 3 grupos, o grupo A recebeu $500 \mathrm{mg} / \mathrm{kg}$ (miligramas por quilo) de vitamina $C$ por via intravenosa a cada 2 dias, começando imediatamente após implante endometriótico, o grupo B também recebeu a mesma quantidade de vitamina $\mathrm{C}$, porém a sua administração foi dada 21 dias após a operação, e o grupo $C$ não recebeu nenhum tipo de suplementação. Todos tiveram os volumes das lesões medidas e os autores tiveram como resultado no grupo A um menor volume de implante com uma diferença estatisticamente significativa em comparação com o grupo $B$, concluindo que uma dieta rica em vitamina $C$ e tão logo seja possível a inclusão de alimentos com essa propriedade na dieta pode ter um efeito supressor na prevenção da indução do implante endometriótico e na regressão dos volumes das lesões de endometriose. 
Diversas revisões relatam que algumas deficiências nutricionais como por exemplo deficiência de vitamina $\mathrm{C}$ no organismo também pode estar associada a etiologia da Síndrome da Fadiga Crônica, um sintoma bastante relatado entre as mulheres com endometriose (BJØRKLUND et al., 2019).

\subsubsection{VITAMINA D}

As vitaminas são micronutrientes, divididos em duas categorias: hidrossolúveis (solúveis em água) e lipossolúveis (solúveis em gordura). A vitamina $D$ faz parte do grupo lipossolúvel. É um nutriente único, pois pode ser obtido não apenas por meio da dieta, mas também pela sua função hormonal obtida pela exposição à radiação solar. Essa vitamina tem ações mais conhecidas no metabolismo ósseo, entretanto suas ações também vêm sendo descritas nas células do sistema imunológico. É encontrada na forma de colecalciferol (vitamina D3) e ergocalciferol (vitamina D2) ambas ainda inativas, mas ao serem ativadas possuem respostas biológicas semelhantes e podem ser sintetizadas comercialmente, além de obtê-las também em forma de suplementos dietéticos e alimentos fortificados. Importante lembrar que a vitamina $D$ também está presente em certos alimentos como peixes, gemas de ovos, cogumelos, queijo, bife de fígado, leite, etc. Cerca de $20 \%$ de vitamina D3 é adquirida com dieta e $80 \%$ é sintetizado pela pele após exposição solar (FÉLIZ et al., 2019; SASSI et al., 2018). O Institute of Medicine preconiza um consumo de $15 \mu \mathrm{g} / \mathrm{d}$ (microgramas por dia) ou $600 \mathrm{UI}$ (Unidades Internacionais) de vitamina D para faixa etária feminina de 1 a 70 anos.

Conforme estudo realizado por Anastasi et al. (2017) avaliou os níveis de vitamina D em 104 pacientes com endometriose diagnosticadas cirurgicamente e a relação potencial entre esses níveis e seus sintomas, a análise do nível de vitamina $D$ foi efetuado por LUMIPULSE®G1200 (Fujirebio, Japão), um sistema de ensaio automatizado. De acordo com o relatório da Fundação Internacional de Osteoporose (IOF, sigla em inglês) o status de vitamina $D$ foi categorizado com os seguintes valores, deficiência: menor que $20 \mathrm{ng} / \mathrm{ml}$ (nanogramas por mililitros); insuficiência: 20$30 \mathrm{ng} / \mathrm{ml}$ e adequação: maior ou igual a $30 \mathrm{ng} / \mathrm{ml}$. A dor foi avaliada usando uma escala visual analógica (EVA) de 10 pontos para cada sintoma de dor como 
dismenorreia, dispareunia e dor pélvica crônica. Nos 104 casos com endometriose, os sintomas de dor tiveram os seguintes resultados: dismenorreia estava ausente em 15 mulheres, dispareunia estava ausente em 50 mulheres e a dor pélvica crônica estava ausente em 57 mulheres. A EVA resultou em um fator associado à deficiência de vitamina D. Já o nível de vitamina $D$ sérica em mulheres com endometriose foi de 21,3 $\mathrm{ng} / \mathrm{ml}$. A deficiência de vitamina $\mathrm{D}$ foi observada em $48 \%$ das mulheres, insuficiência em $32 \%$ e apenas $20 \%$ tinham valores séricos adequados. No geral, a deficiência e insuficiência da vitamina esteve presente em $80 \%$ dos casos. No grupo controle esse nível de vitamina $D$ foi de $32,3 \mathrm{ng} / \mathrm{ml}$, a deficiência e insuficiência de vitamina $D$ foi significativamente mais frequente em mulheres com endometriose do que no grupo controle $(80 \%$ vs. $33,3 \%)$ mostrando uma forte correlação de que pacientes com endometriose possuem níveis mais baixos de vitamina $D$ em comparação com pacientes saudáveis em idade reprodutiva. A endometriose muitas vezes se comporta como uma doença maligna e mostra várias características de uma doença autoimune.

De acordo com estudo de Moini et al. (2016) onde o objetivo foi investigar o efeito da suplementação de vitamina $D$ no tratamento da dismenorreia em mulheres com deficiência dessa vitamina, o tratamento com suplementação oral de vitamina $D$ foi eficaz para diminuir sintomas ligados a endometriose. O estudo clínico duplo-cego randomizado controlado por placebo foi realizado em 60 mulheres com cólicas menstruais, foram divididas aleatoriamente em grupos de tratamento e controle, o grupo tratamento recebeu $50000 \mathrm{UI}$ de vitamina D oral e o grupo controle recebeu placebos semanalmente durante oito semanas. Após dois meses de tratamento, a concentração sérica de vitamina $D$ aumentou significativamente no grupo tratamento apresentando resultado de $55,44 \mathrm{ng} / \mathrm{ml}$, mas não no grupo placebo que teve como resultado um valor de $13,57 \mathrm{ng} / \mathrm{ml}$ de vitamina $D$ sérica. No início do estudo, o grupo placebo, ao final de dois meses de tratamento, 4 pacientes (14,8\%) teve dor leve, 17 $(63 \%)$ dor moderada e 6 pacientes $(22,2 \%)$ teve fortes dores. Já no grupo tratamento com vitamina D a dor era leve em 3 pacientes (13\%), moderado em $16(69,6 \%)$ e grave em 4 pacientes (17,4\%), enquanto após o tratamento $95,7 \%$ das pacientes (22) tinham dor leve, $4,3 \%$ (1) tinha dor moderada e nenhuma delas sentia dor intensa. Com base nos resultados do estudo, parece que a suplementação oral de 
vitamina $D$ com a dose indicada por oito semanas pode melhorar intensidade da dor e diminuir a necessidade de uso de AINEs em pacientes com dismenorreia primária decorrentes da endometriose.

Um estudo observacional feito com 49 pacientes diagnosticadas com endometrioma ovariano (cisto ovariano) foi verificado que 42 mulheres se encontravam com hipovitaminose D. O diâmetro médio do endometrioma ovariano foi de 40,2 $\mathrm{mm}$, enquanto as pacientes com níveis de vitamina $D$ sérica considerados normais foi de $26,7 \mathrm{~mm}$. No entanto, foi concluído que houve uma relação clara e significativa com os níveis sanguíneos de vitamina D e o diâmetro do cisto ovariano (CIAVATTINI et al., 2016).

Um trabalho de reeducação alimentar pode ser um método favorável para que mulheres possam prevenir ou mesmo utilizar como tratamento alternativo para a endometriose (HALPERN et al., 2015).

\subsubsection{VITAMINA E}

A vitamina $E$ é um antioxidante solúvel em gordura que pode proteger os ácidos graxos poli-insaturados na membrana da oxidação, regulando a produção de espécies reativas de oxigênio e modula a transdução de sinais químicos. Vitamina E é o termo coletivo para nomear oito compostos distintos pertencentes a dois grupos: tocoferóis ( $\alpha-, \beta-, \gamma$ - e $\delta$-tocoferóis) e tocotrienóis ( $\alpha-, \beta-, \gamma-$ e $\delta$-tocotrienóis) encontrados nos alimentos. Essas oito formas possuem atividades antioxidantes, mas não podem ser convertidas entre si, e apenas o $\alpha$-tocoferol atende às necessidades de vitamina $E$ humana. As principais fontes dietéticas de vitamina $E$ são os óleos vegetais. Os óleos de soja, girassol, milho, noz, caroço de algodão, palma e gérmen de trigo contêm quantidades relativamente maiores (aproximadamente $50 \mathrm{mg}$ de vitamina E/100 g de óleo) de vitamina $E$ do que outros óleos. As nozes também são boas fontes de vitamina $\mathrm{E}$ (LEE; HAN, 2018).

O Institute of Medicine informa que a ingestão diária de vitamina E é de $15 \mathrm{mg}$ (miligramas) mulheres com faixa etária de 14 anos ou mais. É bem conhecido que o 
estado nutricional é importante para manter as funções normais do sistema imunológico e prevenir ou amenizar as disfunções induzidas por fatores internos ou externos. A ingestão de nutrientes em níveis recomendados ou acima dos recomendados pode retomar ou aumentar ainda mais as funções do sistema imunológico (LEWIS et al., 2019).

Os efeitos do agente antioxidante vitamina $E$, em pacientes com endometriose, foram investigados em uma revisão bibliográfica feita por Harlev et al. (2015) e embora efeitos significativos tenham sido relatados, deve-se notar que a maior parte desses estudos são in vitro ou em animais. Portanto, mais pesquisas são necessárias para esclarecer o papel da vitamina $\mathrm{E}$ na causa da endometriose.

\subsection{ZINCO, RESVERATROL E CURCUMINA COMO TRATAMENTO ADJUVANTE NA ENDOMETRIOSE}

\subsubsection{ZINCO}

É um mineral antioxidante essencial para prevenção da produção e resposta reativa dos radicais livres, está envolvido em várias funções biológicas como resposta ao estresse oxidativo, homeostase, respostas imunológicas e regulação da expressão gênica. O consumo diário de zinco é de $8 \mathrm{mg} /$ dia para mulheres a partir da idade reprodutiva. O zinco pode ser encontrado em uma ampla variedade de alimentos. A ostras por exemplo são mais abundantes em zinco do que qualquer outro alimento. No entanto, as principais fontes de ingestão de zinco são carnes bovinas, vitela, carnes suínas e carne de cordeiro. Outras boas fontes de alimentos como peixes, vegetais, nozes e refeições prontas contêm zinco, mas em quantidades menores (CHASAPIS et al., 2020; INSTITUTE OF MEDICINE, 2001).

Em circunstâncias de estresse oxidativo, os antioxidantes são fundamentais para regular as reações que liberam os radicais livres e prevenir os danos causados nas células. Nutrientes antioxidantes incluídos em uma dieta adequada, com oligoelementos essenciais, como o zinco, melhoram as funções imunológicas exibindo um importante papel protetor (CHASAPIS et al., 2020). 
Um ensaio clínico duplo-cego randomizado efetuado por Zekavat et al. (2015) com duração de três meses, controlado por placebo, onde 120 adolescentes do sexo feminino com dismenorreia primária foram divididas aleatoriamente em dois grupos: um grupo de intervenção (zinco) e um grupo controle (placebo). O zinco foi administrado na forma de cápsula contendo $50 \mathrm{mg} /$ dia de sulfato de zinco, começando no primeiro dia da menstruação e continuando até três dias antes do final da menstruação. A cada mês, a duração e a gravidade da dismenorreia primária foram determinadas. A pontuação de gravidade foi realizada usando um sistema de escala visual analógica de 0-10. Obteve-se como resultado no primeiro mês uma duração substancialmente menor de dor no grupo de zinco (valor $=3.95$ ) em comparação ao grupo placebo (valor $=4.62$ ), enquanto não houve diferença significativa na intensidade da dor entre os grupos, (valor $=6.60)$ e (valor $=6.96)$, respectivamente. No segundo e terceiro mês, a duração da dor no grupo de zinco foram significativamente menores do que no grupo de placebo conforme mostra a Tabela 2. Concluindo, que a duração e a intensidade da dor diminuíram com a ingestão de suplemento oral de zinco sugerindo que esse mineral pode ser usado no tratamento da dismenorreia, sintoma habitual de portadoras de endometriose.

Tabela 2. Comparação da duração da dor e intensidade da dor após administração de cápsula de Sulfato de zinco

\begin{tabular}{|c|c|c|c|c|}
\hline \multicolumn{3}{|c|}{ Duração da dor } & \multicolumn{2}{|c|}{ Intensidade da dor } \\
\hline Tempo & $\begin{array}{l}\text { Grupo } \\
\text { intervenção }\end{array}$ & $\begin{array}{l}\text { Grupo } \\
\text { controle }\end{array}$ & Grupo intervenção & $\begin{array}{l}\text { Grupo } \\
\text { controle }\end{array}$ \\
\hline Linha base & 5,47 & 5,21 & 7,3 & 7,23 \\
\hline Primeiro ciclo & 3,95 & 4,62 & 6,60 & 6,96 \\
\hline $\begin{array}{l}\text { Segundo } \\
\text { ciclo }\end{array}$ & 3,22 & 4,43 & 5,01 & 6,68 \\
\hline Terceiro ciclo & 2,44 & 4,42 & 4,23 & 6,58 \\
\hline
\end{tabular}

Fonte: tabela adaptada de Zekavat et al. 2015 
Em mais um estudo feito por Teimoori et al. (2016) também para avaliar a eficácia do suplemento de zinco em mulheres com cólicas menstruais, 200 participantes com dismenorreia primária foram randomizadas em dois grupos. O grupo de intervenção recebeu zinco e ácido mefenâmico (fármaco do grupo dos anti-inflamatórios não esteroides), e o grupo controle recebeu ácido mefenâmico e um medicamento placebo. Após três meses de tratamento, as mudanças na incidência de dismenorreia e no grau de dor foram medidas em ambos os grupos. O escore médio de dor antes da administração de zinco e ácido mefenâmico no grupo de intervenção foi de 5.3 e após o tratamento foi de 1.2 e no grupo controle, o escore médio de dor antes da administração de ácido mefenâmico e placebo foi de 5.8 e após o tratamento foi de 2.9. A diferença nos níveis de dor antes e posteriormente o tratamento no grupo de intervenção foi de 4.1 e no grupo controle foi de 2.9. Foi descoberto também que $64 \%$ do grupo intervenção e 33\% do grupo controle não apresentaram dismenorreia após o tratamento, constatando que o uso combinado de um suplemento de zinco com um AINE foi superior na redução da dismenorreia se comparado ao uso isolado do ácido mefenâmico.

\subsubsection{RESVERATROL}

O resveratrol é um nutracêutico da classe dos antioxidantes polifenólicos produzido em resposta a um processo de stress mecânico ou biológico que exibe múltiplos efeitos nos seres humanos (SINGH et al., 2019).

É um composto vegetal da dieta natural que é encontrado principalmente na casca e nas sementes da uva (Vitis vinífera e Vitis labrusca), mas também é encontrado nos vinhos e vários outros tipos de alimentos vegetais, (Pisum sativum), eucalipto (Eucalyptus wandoo), amendoim (Arachis hypogacea), chá verde (Camellia sinensis) e frutas vermelhas (PIESZKA et al., 2016; GALINIAK et al., 2019).

Esse antioxidante desempenha um papel interessante como agente terapêutico e quimiopreventivo utilizado no tratamento de várias doenças promovendo prevenção e impedindo a progressão das mesmas. Apresenta efeitos contra diferentes tipos de doenças crônicas relacionadas à inflamação como diabetes, obesidade, doenças 
cardiovasculares, neurodegeneração entre outras condições como por exemplo a endometriose e isso se dá em diferentes vias metabólicas. Além disso o resveratrol exerce efeitos antioxidantes e antiinflamatórios em diversas células como as células endometrióticas e células imunológicas (GALINIAK et al., 2019; RAUF et al., 2019).

Conforme estudo experimental prospectivo feito por Tekin et al. (2015) foi reunido modelo animal com endometriose induzida para comparar os efeitos anti-inflamatórios e anti-angiogênicos do resveratrol com o fármaco análogo do hormônio liberador de gonadotrofina ( $\mathrm{GnRH}$, sigla em inglês), acetato de leuprolida injetável (LUPRON®). Os camundongos foram separados aleatoriamente em quatro grupos onde o grupo 1 recebeu $30 \mathrm{mg} / \mathrm{kg}$ resveratrol por 14 dias, o grupo 2 recebeu $1 \mathrm{mg} / \mathrm{kg}$ de dose única de acetato de leuprolida, o grupo 3 recebeu tanto resveratrol quanto o acetato de leuprolida e o grupo 4 não recebeu nenhuma medicação. $O$ fator de crescimento endotelial (VEGF, sigla em inglês) dos implantes endometrióticos foram avaliados. $O$ plasma e fluído peritoneal foram avaliados também os níveis de IL -6, IL-8 e TNF- $\alpha$ por 14 dias. Nos resultados houve diferença significativa nos tamanhos dos volumes de pré-tratamento $\left(241,147,83,169 \mathrm{~mm}^{3}\right.$ nos grupos 1 , 2, 3 e 4 respectivamente) nos resultados pós-tratamento os implantes endometrióticos nos grupos 1, 2 e 3 foram menores do que no grupo 4 que não recebeu nenhum medicamento ou composto, e essa diferença foi estatisticamente significativa $\left(27,41,65\right.$, e $297 \mathrm{~mm}^{3}$ respectivamente). Os níveis de IL-6, IL-8 e TNF-a no plasma e fluido tiveram valores estatisticamente menores nos grupos 1 e 2 do que nos grupos 3 e $4(p<0.001)$, tendo como resposta do estudo que o resveratrol sozinho inibe a inflamação e angiogênese na endometriose sendo um agente potencial para o tratamento da doença. Em contraste, a combinação de acetato de leuprolida e resveratrol diminuiu o efeito antiinflamatório e efeitos anti-angiogênicos de cada agente. Uma vez que o resveratrol é amplamente utilizado como uma terapia alternativa para uma variedade de condições, pode prejudicar a eficácia do fármaco. Portanto, deve-se ter cuidado quando usado em combinação com outros agentes farmacológicos.

Estudo feito por Khazaei at el. (2020) teve o objetivo de investigar o efeito de diferentes concentrações de resveratrol no crescimento de tecido endometrial humano e na 
angiogênese em um modelo tridimensional in vitro de endometriose. Foram analisados tecido endometrial de mulheres sem endometriose e com endometriose em grau III e IV. Cada tecido de biópsia recebeu por 21 dias concentrações de 0 (controle) 10, 50, 100 e $200 \mu \mathrm{m}$ (micrómetros) de resveratrol e o tecido controle não recebeu nenhuma quantidade de resveratrol. Métodos de pontuação foram usados para verificar as mudanças no tecido, incluindo invasão celular, formação de monocamada e angiogênese. O tecido controle não apresentou alterações morfológicas no primeiro dia de cultura, já o tecido endometriose mostrou no vigésimo primeiro dia, extenso crescimento de células endoteliais (angiogênese), crescimento de estroma (tecido de sustentação formado por tecido conjuntivo e vasos sanguíneos) e crescimento epitelial. Durante a cultura de três semanas, a tendência de crescimento de tecido aumentou de maneira dependente da dose e do tempo, doses mais baixas (10 e $50 \mu \mathrm{m}$ ) de resveratrol, mas em concentrações de 100 e $200 \mu \mathrm{m}$, a tendência de crescimento inibiu completamente em comparação com o início do período da cultura. O estudo mostrou que maiores concentrações de resveratrol (200 $\mu \mathrm{m})$ inibiu o crescimento endometrial e a angiogênese na cultura tridimensional de endometriose. O resveratrol também diminuiu a secreção de óxido nítrico e aumentou expressão de genes apoptóticos em células endometriais.

\subsubsection{CURCUMINA}

A curcumina substância ativa da cúrcuma (Curcuma longa) é uma planta relacionada à família do gengibre (Zingiberaceae), de origem indiana. É um polifenol lipofílico e pode funcionar como anticâncer, antibiótico, anti-inflamatório devido suas propriedades antioxidantes. A cúrcuma é uma especiaria comum usada em preparações culinárias na Índia e em outros países asiáticos devido ao seu sabor levemente picante e de cor vibrante (KOTHA; LUTHRIA, 2019).

O uso de suplementos dietéticos e nutracêuticos está ganhado popularidade ao longo desses últimos anos, por apresenta alguns papéis terapêuticos potenciais como um composto anti-inflamatório a cúrcuma desperta interesse. Alguns estudos recentes mostram os benefícios da cúrcuma como tratamento complementar na endometriose (VALLÉE; LECARPENTIER, 2020). 
Estudo experimental realizado por Kizilay et al. (2017) examinou os efeitos da curcumina e/ou deferoxamina (quelante de ferro) na proliferação celular em um modelo de endometriose induzida em modelo animal. Os animais foram divididos em 3 grupos, grupo A, tratados apenas com o veículo utilizado para curcumina e deferoxamina, grupo B, tratado com curcumina (100 mg/kg) e grupo C, tratado com deferoxamina e curcumina (100 mg/kg) e tiveram os seguintes resultados: o tamanho do implante endometrial aumentou no Grupo A (valor antes do estudo $=10,98 \mathrm{~mm}^{3}$ / valor depois do estudo $=32,89 \mathrm{~mm}^{3}$ ) mas 0 tratamento com curcumina $\mathrm{e}$ edeferoxamina reduziu o tamanho do implante $\left(23,33 \mathrm{~mm}^{3}\right.$ no grupo B e C). Em comparação com células endometriais eutópicas, as células ectópicas, tiveram diminuições significativas na imunorreatividade do antígeno nuclear de célula proliferativa (PCNA, sigla em inglês). Valores antes do estudo: grupo $A=111,43 \mathrm{mg} / \mathrm{l}$ grupo $B=100,00 \mathrm{mg} / \mathrm{l}$ e grupo $C=91,25 \mathrm{mg} / \mathrm{l}$ (miligramas por litros) valores posteriores ao estudo: 106,83 mg/l; 69,00 mg/l; e 67,00 mg/l nos grupos A, B e C respectivamente. Concluindo que o tratamento com curcumina sozinho e/ou em combinação com deferoxamina contribuiu para uma redução no tamanho do implante endometrial e proliferação celular na endometriose. Os agentes quelantes de ferro também podem agir da mesma maneira quando usado em mulheres com endometriose

Outro estudo elaborado por Chowdhury et al. (2019) usou culturas primárias de células estromais derivadas de indivíduos com endométrio eutópico de endometriose (EESC) células estromais endometriais normais (NESC) para avaliar níveis basais de expressão de quimiocinas e citocinas pró-inflamatórias e pró-angiogênicas. E como resultado o tratamento de EESC e NESC com curcumina reduziu significativamente e de forma dependente da dose a secreção de quimiocinas e citocinas ao longo do tempo. Houve uma morte celular apoptótica de $100 \%$ em 72 horas em resposta a 40 $\mu \mathrm{g} / \mathrm{ml}$ de curcumina. Os resultados sugerem que a curcumina tem potencial terapêutico para anular a ativação de quimiocinas e citocinas. A eficácia de uma composição incluindo curcumina para redução do tamanho de implantes endometrióticos em modelo animal com 25 camundongos em estudo realizado por Boroumand et al. (2019) mostrou resultados benéficos onde Nanofibras carregadas 
$45 \mathrm{mg}$ (miligramas) de curcumina foram implantadas na cavidade peritoneal do grupo de tratamento. $O$ grupo de controle não recebeu tratamento. $O$ tamanho da lesão foi visto através de teste de liberação dessas nanofibras. Após 21 dias, as lesões endometrióticas e os cistos diminuíram significativamente dependendo do tempo de tratamento onde num período de 30 dias as lesões diminuíram em torno de $50 \%$ em comparação com o grupo controle, mostrando uma cavidade peritoneal sem sinais de características de endometriose.

\section{CONCLUSÃO}

A endometriose é considerada uma patologia de difícil entendimento e por esse motivo o conhecimento tanto dos profissionais de saúde quanto dos familiares dessas pacientes e da população no geral sobre essa condição merece atenção e cuidado. É uma enfermidade de difícil diagnóstico e demorado considerada crônica, porém sem evolução para malignidade, mas apresenta danos graves no bem-estar geral das mulheres.

Os estudos sobre o efeito da terapia dietética na endometriose são escassos, mesmo tendo grande importância no auxílio do tratamento de demais doenças crônicas e não somente na endometriose. Porém, como em uma série de doenças crônicas, a atribuição dos nutrientes no mecanismo de comportamento de tais doenças tem recebido mais atenção nas pesquisas.

Para o tratamento e controle da endometriose, os medicamentos hormonais são as únicas opções disponíveis atualmente, e muitas vezes sem sucesso terapêutico e com inúmeros efeitos colaterais.

Esta revisão de literatura permitiu concluir que há indícios de que determinados alimentos e nutrientes motivam tanto a patogênese quanto a progressividade da doença, levando à oportunidade de tratamentos eletivos e adjuvantes para mulheres que tanto sofrem com essa doença e por esse motivo prevenir o avanço da doença ou reduzir seus sintomas, mudanças no estilo de vida devem ser consideradas. 
Portanto, mudar a dieta é uma razão essencial. Sabe-se que a terapêutica da endometriose é multidisciplinar, como tal, as interferências neste campo também devem ser necessárias a inserção de nutricionistas às equipes para que nos próximos anos tenhamos um papel indispensável na prevenção e nos resultados terapêuticos do manejo da doença.

\section{REFERÊNCIAS}

AGUILAR-AGUILAR, Elena. Desórdenes menstruales: lo que sabemos de la terapia dietética-nutricional. Nutrición Hospitalaria, Spanish. v. 37, n. 2, p. 52-56. 2020.

AKIOL, Alpaslan.; ŞIMŞEK, Memet.; ILHAN, Raşit; CAN, Behzat.; BASPINAR, Melike et al. Efficacies of vitamin $D$ and omega-3 polyunsaturated fatty acids on experimental endometriosis. Taiwanese Journal of Obstetrics and Gynecology, [s.I.], v.55, n.6, p. 835-839, 2016.

AMARAL, Patrícia Pires. Tratamento farmacológico. In: Aspectos diagnósticos e terapêuticos da endometriose. 2017. 35 f. Monografia (Bacharel em Farmácia) Faculdade de Educação e Meio Ambiente - FAEMA. Rondonia, 2017.

ANASTASI, Emanuela.; FUGGETTA, Eliana.; DE VITO, Corrado.; MIGLIARA, Giuseppe.; VIGGIANI, Valentina. et al. Low levels of 25-OH vitamin D in women with endometriosis and associated pelvic pain. Clinical Chemistry and Laboratory Medicine (CCLM), [s.I.] v. 55, n. 12, 2017.

ANDRES, Marina Paula.; BORRELLI, Giuliano Moysés.; ABRÃO, Mauricio Simões. Endometriosis classification according to pain symptoms: can the ASRM classification be improved? Best Practice \& Research Clinical Obstetrics \& Gynaecology, [s.I.], v. 51, p. 111-118, 2018.

BAUMART, Genaína Pereira. A doença da mulher moderna. p. 5 In: BAUMART, Genaína Peraiera. Vamos falar sobre endometriose? 2015. 11 f. Trabalho de Conclusão de Curso (Bacharel em Jornalismo) - Revista Ciência em Pauta - Especial 
Endometriose - Universidade Federal de Santa Catarina. Centro de Comunicação e Expressão. Jornalismo. 2015.

BENJAMIM, Cicero Jonas Rodrigues.; ALCANTARA, Guilherme Correia.; NOVAIS, Palloma Lima Couto.; LOPES, Janeanne Nascimento Silva.; ROCHA, Elida Mara Braga. 0 consumo de ômega 3 e 6 e a sua relação com doenças crônicas não transmissíveis. Revista E-Ciência, [s.I.], v. 6, n. 2, 2019.

BISHOP, Lauren A. Management of chronic pelvic pain. Clinical Obstetrics and Gynecology. [s.I.], 3th ed. v. 60, p. 524-530, Sept. 2017.

BJØRKLUND, Geir; DADAR, Maryam.; PEN, Joeri J.; CHIRUMBOLO, Salvatore.; AASETH, Jan. Chronic fatigue syndrome (CFS): Suggestions for a nutritional treatment in the therapeutic approach. Biomedicine \& Pharmacotherapy, [s.I], v. 109, p. 1000-1007, 2019.

BOROUMAND, Safieh.; HOSSEINI, Sara.; PASHANDI, Zaiddodine.; FARIDI-MAJIDI, Reza.; SALEHI, Mohammad. Curcumin-loaded nanofibers for targeting endometriosis in the peritoneum of a mouse model. Journal of Materials Science: Materials in Medicine, [s.I.], v. 31, n. 8, 2019.

BOTHAM, Katheen M.; MAYES, Peter A. Lipídeos de importância fisiológica. In: RODWELL, Victor W.; BENDE, David A.; BOTHAM, Kathleen M.; KENNELLY, Peter J.; WEIL P. Anthony. Bioquímica Ilustrada de Harper. 30. ed. Porto Alegre: AMGH Editora Ltda., 2017, 832 p. seção V, cap. 21, 2017. Disponível em: < https://books.google.com.br/books?id=J1N4DQAAQBAJ\&dq=Bioqu\%C3\%ADmica+ll ustrada+de+Harper\&hl=pt-BR\&source=gbs_navlinks_s>. Acesso em: 30 set. 2020.

BOVE, Simone Garcia Pereira.; DE SOUZA, Sabrina Macedo. A influência dos alimentos no tratamento da endometriose. AEMS Revista Conexão Eletrônica, Mato Grosso do Sul, v.16, n. 1, p. 771-778, 2019. 
BRASIL. Ministério da Saúde. Secretaria de atenção à saúde. Departamento de Atenção Básica. Guia alimentar para a população brasileira, 2. ed. Brasília, 2014. $156 \mathrm{p}$.

BRASIL. Ministério da Saúde. Secretaria de Atenção à Saúde. Portaria ํo 879, de 12 de julho de 2016. Protocolo Clínico e Diretrizes Terapêuticas da Endometriose. Diário Oficial [da] União da República Federativa do Brasil. Brasília, DF, 26 p. 2016. Disponível em:

http://conitec.gov.br/images/Protocolos/pcdt_endometriose_2016.pdf>. Acesso em: 25 out. 2020.

BRASIL. Sociedade Brasileira de Alimentação e Nutrição. SBAN. Como manter hábitos saudáveis em tempos de distanciamento social. 2020. Disponível em:< http://www.sban.org.br/blog-sban.aspx>. Acesso em: 28 out. 2020.

CACCIATORI, Felipe Antônio.; MEDEIROS, João Pedro Ferri. Endometriose: uma revisão da literatura. Revista de Iniciação Científica. Santa Catarina, v. 13, n. 1, 2015.

CAMBIAGHI, Arnaldo Schizzi.; DE SOUZA ROSA, Débora. Fertilidade e alimentação: Guia alimentar para homens e mulheres que desejam preservar ou melhorar sua fertilidade. São Paulo: La Vida Press, 2016, 390 p. Disponível em: $<$ https://play.google.com/books/reader?id=EQZuDwAAQBAJ\&hl=pt\&pg=GBS.PP1>. Acesso em: 8 abr. 2020.

CARDENAS-TROWERS, Olivia.; MEYER, Isuzu.; MARKLAND, Alayne.; RICHTER, Holly E.; ADDIS, Ilana. A review of Phytoestrogens and Their Association with Pelvic Floor Conditions. Female Pelvic Medicine \& Reconstructive Surgery, [s.I.], v. 24, 3th ed. p. 193-202, 2018.

CARR, Anitra C.; MAGGINI, Silvia. Vitamin C and immune function. Nutrients, v. 9, 11th ed. p. 111-211, 2017. 
CHANTALAT, Elodie.; VALERA, Marrie Cécile.; VAYSSE, Charlotte.; NOIRRIT, Emmanuelle.; RUSIDZE, Mariam. et al. Estrogen Receptors and Endometriosis. International Journal of Molecular Sciences, [s.I.], v. 21, 8th ed. 2020.

CHASAPIS, Christos T.; NTOUPA, Panagoula-Stamatina A.; SPILIOPOULOU, Chara A.; STEFANIDOU, Maria E. Recent aspects of the effects of zinc on human health. Archives of Toxicology, [s.I.], v. 94 p., 1443-1460, 2020.

CHOWDHURY, Indrajit.; BANERJEE, Saswati.; DRISS, Adel.; XU, Wei.; MEHRABI, Sherifeh. et al. Curcumin attenuates proangiogenic and proinflammatory factors in human eutopic endometrial stromal cells through the NF-KB signaling pathway. Journal of Cellular Physiology, [s.I.], v. 234, 5th ed. p. 6298-6312, 2019.

CHRIST, Anette.; LAUTERBACH, Mario.; LATZ, Eicke. Western Diet and the Immune System: An Inflammatory Connection. Immunity, [s.I.], v. 51, n. 5, p. 794811, 2019.

CIAVATTINI, Andrea.; SERRI, Matteo.; CARPINI, Giovanni. DELLI.; Morini, STEFANO.; CLEMENTE, Nicoló. Ovarian endometriosis and vitamin D serum levels. Gynecological Endocrinology, [s.I.], v. 33, 2th ed. p. 164-167, 2016.

DE ARRUDA COSTA, Maria Clara Ribeiro.; DE OLIVEIRA, Maria Heloisa Moura.; PONTES, Edson Douglas Silva.; DA SILVA, Ana Paula Ferreira.; DE ARAÚJO SILVA, Ana Paula et al. A Influência Benéfica da Dietoterapia em Portadoras de Endometriose. International Journal of Nutrology, [s.I.], v. 11, 2018.

DE KORWIN, J. D.; CHICHE, L.; BANOVIC, L.; GHALI, A.; DELLIAUX, S. et al. Le syndrome de fatigue chronique: une nouvelle maladie? La Revue de médecine interne, [s.I.], v. 37, n. 12, p. 811-819, 2016.

DE MARQUI, ALESSANDRA BERNADETE TROVÓ. Endometriose: do diagnóstico ao tratamento. Revista de Enfermagem e Atenção à Saúde, Minas Gerais, v. 3, n. 2, 2014. 
DONNEZ, Jaccques.; BINDA, Maria Mercedes.; DONNEZ, Olivier.; DOLMANS, MarieMadeleine. Oxidative stress in the pelvic cavity and its role in the pathogenesis of endometriosis. Fertility and Sterility, [s.I.], v. 106, n. 5, p. 1011-1017, 2016.

ERTEN, Ozlem Ulas.; ENSARI, Tuğba Altun.; DILBAZ, Berna.; CAKIROGLU, Huseyin.; ALTINBAS, Sadimam.; KIYKAC Altinbas. et al. Vitamin C is effective for the prevention and regression of endometriotic implants in an experimentally induced rat model of endometriosis. Taiwanese Journal of Obstetrics and Gynecology, [s.l.], v. 55, 2th ed. p. 251-257, 2016.

FACCHIN, Federica.; BARBARA, Giussy.; SAITA, Emanuela.; MOSCONI, Paola.; ROBERTO, Anna. et al. Impact of endometriosis on quality of life and mental health: pelvic pain makes the difference. Journal of Psychosomatic Obstetrics \& Gynecology, [s.I.], v. 36, n. 4, p. 135-141, 2015.

FÉLIZ, Débora Azevedo.; DE ANDRADE, Romário Pereira.; DO ROSÁRIO, Kauane Durães. Influência da vitamina $D$ na saúde humana. Revista de Iniciação Científica e Extensão, [s.I.], v. 2, n. 3, p. 163-166, 2019.

FIALA, Ludek.; BOB, Petr.; RABOCH, Jiri. Oncological markers CA-125, CA 19-9 and endometriosis. Medicine, [s.I.], v. 97, n. 51, 2018.

FUNDAÇÃO INTERNACIONAL DE OSTEOPOROSE. IOF. [s. I.]. Disponível em: $<$ https://www.osteoporosis.foundation/health-

professionals/prevention/nutrition/vitamin-d.>. Acesso em: 24 out. 2020.

GALINIAK, Sabina.; AEBISHER, David.; BARTUSIK-AEBISHER, Dorota. Health benefits of resveratrol administration. Acta Biochimica Polonica, [s.I.], v. 66, n. 1, 2019.

GARCIA, Jéssica Leite. Impacto da ingestão de carboidratos simples e gordura sobre parâmetros metabólicos, inflamatórios e pró-oxidantes no plasma e no tecido adiposo independente de obesidade. 2018. 67 f. Dissertação (Mestrado em 
Patologia) - Faculdade de Medicina de Botucatu, Universidade Estadual Paulista Júlio de Mesquita Filho, São Paulo, 2018.

GHEDINI, Natalia Simonian Rodrigues Valente.; ASSUMPCAO, Daniela De. BARROS, Marilisa Berti Azevedo; DOMENE, Semíramis Martins Álvare. Omega6: omega3 fatty acids in the diet: results from a population-based study. In: 21 st International Congress of Nutrition, 2017, Buenos Aires. Annals Of Nutrition And Metabolism, Buenos Aires: Karger, 2017. p. 628-628. Disponível em: < https://repositorio.unifesp.br/handle/11600/55396>. Acesso em: 28 out. 2020.

GOLFIER, Fraçois.; CHANAVAZ-LACHERAY, Isabella.; DESCAMPS, Philippe.; AGOSTINI, Aubert.; POILBLANC, Mathieu. et al. The definition of Endometriosis Expert Centres. Journal of Gynecology Obstetrics and Human Reproduction, [s.I.], 5. ed. v. 47, p. 179-181, 2018.

HALPERN, Gabriela.; SCHOR, Eduardo.; KOPELMAN, Alexander. Nutritional aspects related to endometriosis. Revista da Associação Médica Brasileira, v. 61, n. 6, p. 519-523, 2015.

HARKINS, Gerald J. Female Pelvic Pain. Seminars in Reproductive Medicine, [s.l.], v. 36, n. 2, p. 97-98, 2018.

HARLEV, Avi.; GUPTA, Sajal.; AGARWAL, Ashok. Targeting oxidative stress to treat endometriosis. Expert Opinion on Therapeutic Targets, [s.I.], v. 19, n. 11, p. 1447-1464, 2015.

HEARD, Melissa E.; MELNYK, Stepan B.; SIMMEN, Frank A.; YANG, Yanqing.; PABONA, John Mark. P. et al. High-fat Diet Promotion of Endometriosis in an Immunocompetent Mouse Model is Associated with Altered Peripheral and Ectopic Lesion Redox and Inflammatory Status. Endocrinology, [s.I.], v. 157, n. 7 , p. 2870-2882, 2016.

HENRIQUE, Vanessa Alves.; NUNES, Carla Dos Reis.; AZEVEDO, Fabíola Teixeira.; PEREIRA, Silvia Menezes De Faria.; BARBOSA, João Batista. et al. Alimentos 
funcionais: aspectos nutricionais na qualidade de vida. Aracaju: Editora EdIFS, 2018, $57 \mathrm{p}$.

HILL, Christopher J.; FAKHRELDIN, Marwa.; MACLEAN, Alison.; DOBSON, Lucy.; NANCARROW, Lewis. et al. Endometriosis and the Fallopian Tubes: Theories of Origin and Clinical Implications. Journal of clinical medicine, [s.l.], v. 9, 6th ed. 2020.

HOSPITAL DAS CLÍNICAS. Faculdade de medicina. UNESP. Endometriose. Botucatu. Disponível em: <http://www.hcfmb.unesp.br/endometriose/>. Acesso em: 28 out. 2020.

HSU, Albert L.; KHACHIKYAN, Isabella.; STRATTON, Pamela. Invasive and noninvasive methods for the diagnosis of endometriosis. Clinical Obstetrics and Gynecology, [s.I.], 2th ed. v. 53, p. 413-419, June 2010.

INSTITUTE OF MEDICINE. Dietary reference intakes for vitamin C, vitamin E, selenium, and carotenoids. The National Nacional Academy Press, Washington, 2000.

JURKIEWICZ-PRZONDZIONO, Joanna.; LEMM, Magdala.; KWIATKOWSKAPAMUŁA, Anna.; ZIÓŁKO, Ewa.; WÓJTOWICZ, Mariusz K. Influence of diet on the risk of developing endometriosis. Ginekologia polska, [s.I.], v. 88, n. 2, p. 96-102, 2017.

KARLSSON, Jenny Vennberg.; PATEL, Harshida.; PREMBERG, Asa. Experiences of health after dietary changes in endometriosis: a qualitative interview study. BMJ Open, [s.I.], 2th ed. v. 10, 2019.

KAUR, Kulvinder Kochar.; ALLAHBADIA, Gautam. An update on pathophysiology and medical management of endometriosis. Advances in Reproductive Sciences, [s.l.], v. 4, n. 2, May 2016. 
KHAZAEI, Mohammad Rasool.; RASHIDI, Zahra.; CHOBSAZ, Farzaneh.; NIROMAND, Elham.; KHAZAEI, Mozafar. Inhibitory effect of resveratrol on the growth and angiogenesis of human endometrial tissue in an In Vitro threedimensional model of endometriosis. Reproductive Biology, [s.l.], 2020.

KIZILAY, Gulnur.; UZ, Yesim Hulya.; SEREN, Gulary.; ULUCAM, Enis.; YILMAZ, Ali. et al. In vivo effects of curcumin and deferoxamine in experimental endometriosis. Advances in Clinical and Experimental Medicine, [s.I.], v. 26, n. 2, p. 207-213, 2017.

KOBAYASHI, Hiroshi. Potential scenarios leading to ovarian cancer arising from endometriosis. Redox Report, v. 21, 3th ed. p. 119-126, 2016.

KODAMAN, Pinar H. Current Strategies for Endometriosis Management. Obstetrics and Gynecology Clinics, [s.I.], v. 42, 1th ed. p. 87-101, 2015. KOTHA, Raghavendhar R.; LUTHRIA, Devanand L. Curcumin: biological, pharmaceutical, nutraceutical, and analytical aspects. Molecules, [s.I.], v. 24, 16th ed. p. 2930, 2019.

KUHN, Annette. Chronic pelvic pain. Therapeutische Umschau, [s.I.], 9th ed. v. 75, p. $\quad 573-575, \quad 2019 . \quad$ Disponível em: <https://pubmed.ncbi.nlm.nih.gov/31113315/?fromterm=Chronic+pelvic+pain\&fr ompos=3>. Acesso em: 27 maio 2020.

LEE, Ga. Young.; HAN, Sung. Nim. The Role of Vitamin E in Immunity. Nutrients, [s.l.], v. 10, 11th ed. p. 1614, 2018.

LEWIS, Erin Diane.; MEYDANI, Simim Nikbin.; WU, Dayong. Regulatory role of vitamin $E$ in the immune system and inflammation. IUBMB Life, [s.I.], v. 71, 4th ed. p. 487-494, 2019.

MABROUK, Mohamed.; MONTANARI, Giulia.; GUERRINI, Manuela.; VILLA, Gioia.; SOLFRINI, Serena. et al. Does laparoscopic management of deep infiltrating 
endometriosis improve quality of life? A prospective study. Health and Quality of Life Outcomes, [s.I] v. 9, n. 98, 2011.

MACER, Matthew Lathan.; TAYLOR, Hugh S. Endometriosis and infertility: a review of the pathogenesis and treatment of endometriosis-associated infertility. Obstetrics and Gynecology Clinics, United States of America, 4th ed. v. 39, p. 535-549, 2012.

MILLOCHAU, Jenny-Claude.; ABO, Carole.; DARWISH, Basma.; HUET, Emmanuel.; DIETRICH, Gauthier. et al. Continuous amenorrhea may be insufficient to stop the progression of colorectal endometriosis. Journal of Minimally Invasive Gynecology, [s.l], v. 23, n. 5, p. 839-842, 2016.

MOINI, Ashraf.; EBRAHIMI, Tabandeh; SHIRZAD, Nooshin.; HOSSEINI, Reihaneh.; RADFAR, Mania. et al. The effect of vitamin $D$ on primary dysmenorrhea with vitamin $D$ deficiency: a randomized double-blind controlled clinical trial. Gynecological Endocrinology, [s.l.], v. 32, n. 6, p. 502-505, 2016.

NÁCUL, Andrea Prestes.; SPRITZER, Poli Mara. Aspectos atuais do diagnóstico e tratamento da endometriose. Revista Brasileira de Ginecologia e Obstetrícia, Rio de Janeiro v. 32, n. 6, 2010.

NASIRI, Nahid.; MOIN, Ashraf.; EFTEKHARI-YAZDI, Poopak.; KARIMIAN, Leila.; SALMAN-YAZDI, Reza. Oxidative Stress Statues in Serum and Follicular Fluid of Women with Endometriosis. Cell Journal (Yakhteh), [s.I.], v. 18, n. 4, p. 582-587, 2017.

NEUHOUSER, Marian L. The importance of healthy dietary patterns in chronic disease prevention. Nutrition Research, [s.I.], v. 70, p. 3-6, 2019.

NNOAHAM, Kelechi E.; HUMMELSHOJ, Lone.; WEBSTER, Premila.; D'HOOGHE, Thomas.; NARDONE, Fiorenzo De Cicco. et al. Impact of endometriosis on quality of life and work productivity: a multicenter study across ten countries. Fertility and Sterility, [s.l.], 2th ed. v. 96, p. 366-373, 2011. 
NODLER, James L.; DIVASTA, Amy. D.; VITONIS, Allison F.; KAREVICIUS, Sarah.; MALSCH, Maggie. et al. Supplementation with vitamin $\mathbf{D}$ or $\omega-3$ fatty acids in adolescent girls and young women with endometriosis (SAGE): a double-blind, randomized, placebo-controlled trial. American Journal of Clinical Nutrition, [s.I.], v. 112, p. 229-236, 2020.

OTENG, Antwi-Boasiako.; KERSTEN, Sander. Mechanisms of action of trans fatty acids. Advances in Nutrition, [s.I.], v. 11, n. 3, p. 697-708, 2020.

PEREIRA, Francisco Edson Ximenes. GOMES.; MEDEIROS, Francisco das Chagas.; ROCHA, Hermano Alexandre Lima.; SILVA, Karine Saraiva da. et al. Effects of omega-6/3 and omega-9/6 nutraceuticals on pain and fertility in peritoneal endometriosis in rats. Acta Cirúrgica Brasileira, São Paulo, v. 34, n. 4, 2019.

PIESZKA, Marek.; SZCZUREK, Paulina.; ROPKA-MOLIK, Katarzyna.; OCZKOWICZ, Maria.; PIESZKA, Magdalena. Rola resweratrolu w regulacji metabolizmu komórkowego. Postepy Higieny i Medycyny Doswiadczalnej, [s.I.], v. 70, p. 117-123, 2016.

PODGAEC, Sérgio.; CARAÇA, Daniel Bier; LOBEL Alexandre.; BELLELIS Patrick.; LASMAR, Bernardo Portugal.; LINO, Carlos Augusto. et al. Endometriose. Federação Brasileira das Associações de Ginecologia e Obstetrícia, Febrasgo, Femina. São Paulo, v. 48, n. 4, p. 233-237, 2018. Disponível em: < https://www.febrasgo.org.br/media/k2/attachments/FeminaZ2020Z48Z4ZZWebZ1.pdf>. Acesso em: 13 set. 2020.

PODGAEC, Sérgio. Endometriose - Coleção Febrasgo. 1. ed. Rio de Janeiro: Editota Elsevier Ltda., 2015. 312 p. Disponível em: < https://books.google.com.br/books/about/Endometriose.html?id=Yd12BgAAQBAJ\&pr intsec=frontcover\&source=kp_read_button\&redir_esc $=\mathrm{y} \# \mathrm{v}=0$ nepage \&q\&f=false> . Acesso em: 22 set. 2020.

PORFÍRIO, Gabriela Pimentel.; IRIE, Gabriela Rister Figueiredo.; BATISTA, Letícia Cassimiro.; DE MARQUI, Alessandra Bernadete Trovó. et al. $\mathrm{O}$ papel da dieta na 
etiologia da endometriose. Braspen Journal, São Paulo, v. 32, n. 2, p. 183-188, June 2017.

PORTO, Beatriz Taliberti da Costa.; RIBEIRO, Helizabet Salomão Abdala Ayrosa.; GALVÃO, Maria Antonieta Longo.; SEKULA, Vanessa. Gozzo.; ALDRIGUI, José Mendes. et al. Classificação histológica e qualidade de vida em mulheres portadoras de endometriose. Revista Brasileira de Ginecologia e Obstetrícia, Rio de Janeiro, v. 37, n. 2, fev. 2015.

RAMIN-WRIGHT, Annika.; SCHWARTZ, Alexandra Sabrina Kohl.; GERAEDTS, Kirsten.; RAUCHFUSS, Martina.; WÖLFLER, Monika Martina. et al. Fatigue-a symptom in endometriosis. Human Reproduction, [s.I.], v. 33, n. 8, p. 1459-1465, 2018.

RAUF, Abdur.; IMRANET, Muhammad.; SULERIA, Hafiz Ansar Rasul.; AHMAD, Bashir.; PETERS, Dennis G. et al. A comprehensive review of the health perspectives of resveratrol. Food \& function, [s.I.], 12th ed. p. 4284-4305, 2017.

RODRIGUES, Pamela dos Santos Costa.; SILVA, Thiago Augusto Soares Monteiro da.; SOUZA, Marilei De Melo Tavares E. Endometriose: importância do diagnóstico precoce e atuação da enfermagem para 0 desfecho do tratamento. Revista Pró-UniverSUS, Rio de Janeiro, v. 6, n. 1, p. 13-16, 2015.

SAGUYOD, Sofia Jade U.; KELLEY, Angela S.; VELARDE, Michael C.; SIMMEM, Rosalia C M. Diet and endometriosis-revisiting the linkages to inflammation. Journal of Endometriosis and Pelvic Pain Disorders, [s.l.], v. 10, n. 2, p. 51-58, 2018.

SAMIMI, Mansooreh.; POURHANIFEH, Mohammad Hossein; MEHDIZADEHKASHI, Abolfazl.; EFTEKHAR, Tahereh.; ASEMI, Zatollah. The role of inflammation, oxidative stress, angiogenesis, and apoptosis in the pathophysiology of endometriosis: Basic science and new insights based on gene expression. Journal of Cellular Physiology, [s.I.], v. 234, 11th ed. p. 19384-19392, 2019. 
SÃO BENTO, Paulo Alexandre de Souza; MOREIRA, Martha Cristina Nunes. A experiência de adoecimento de mulheres com endometriose: narrativas sobre violência institucional. Ciência \& Saúde Coletiva, [s.l.], v. 22, n. 9 p. 3023-3032, 2017.

SASSI, Francesca.; TAMONE, Cristina.; D’AMELIO, Patrizia. Vitamin D: Nutrient, Hormone, and Immunomodulator. Nutrients, [s.I.], v. 10, n. 11, 2018.

SCHINK, M.; KONTUREK, P. C.; HERBERT, S. L.; RENNER, S. P.; BURGHAUS, S. et al. Different nutrient intake and prevalence of gastrointestinal comorbidities in women with endometriosis. Journal of Physiology and Pharmacology, [s.I.], v. 70, n. 2, p. 255-268, 2019.

SCUTIERO, Gennaro.; IANNONE, Piergiorgio.; BERNARDI, Giulia.; BONACCORSI, Gloria.; SPADARO, Savino. et al. Oxidative Stress and Endometriosis: A Systematic Review of the Literature. Oxidative Medicine and Cellular Longevity, [s.I.], v. 2017, 7 p. 2017.

SETÄLÄ, Marjaleena.; HÄRKKI, Päivi.; MATOMÄKI, Jaakko.; MÄKINEN, Juha.; KÖSSI, Jyrki. et al. Sexual functioning, quality of life and pelvic pain 12 months after endometriosis surgery including vaginal resection. Acta Obstetricia et Gynecologica Scandinavica, [s.I.], 6th ed. v. 91, p. 692-698, June 2012.

SHEN, Airong.; XU, Shengnan.; MA, Yange.; GUO, Huanhuan.; LI, Canyu. et al. Diagnostic value of serum CA125, CA19-9 and CA15-3 in endometriosis: A metaanalysis. Journal of International Medical Research, [s.I.], 5th ed. v. 43, p. 599-609, 2015.

SINGH, Akhand Pratap.; SINGH, Rachna.; VERMA, Sumit Singh.; RAl, Vipin.; KASCHULA, Catherine $\mathrm{H}$. et al. Health benefits of resveratrol: Evidence from clinical studies. Medicinal Research Reviews, [s.I.], v. 39, 5th ed. p. 1851-1891, 2019.

SOARES, Elaine Dos R.; MONTEIRO, Elisa B.; DA SILVA, Renata C.; BATISTA, Aline.; SOBREIRA, Flávia. et al. Compostos bioativos em alimentos, estresse 
oxidativo e inflamação: uma visão molecular da nutrição. Revista Hospital Universitário Pedro Ernesto, Rio de Janeiro, v. 14, n. 3, p. 64-72, 2015.

TANBO, Tom.; FEDORCSAK, Peter. Endometriosis-associated infertility: aspects of pathophysiological mechanisms and treatment options. Acta Obstetricia et Gynecologica Scandinavica, [s.I.], v. 96, p. 659-667, 2016.

TANG, Zi-Run.; ZHANG, Rui.; LIAN, Zheng-Xing.; DENG, Shou-Long. et al. Estrogenreceptor expression and function in female reproductive disease. Cells, [s.I.], v. 8, n. 10, p. 1123, 2019.

TEIMOORI, Batool.; GHASEMI, Marzieh.; HOSEINI, Zeinab Sadat Amir.; RAZAVI, MARYAM. The efficacy of zinc administration in the treatment of primary dysmenorrhea. Oman Medical Journal, [s.I.], v. 31, n. 2, p. 107-111, 2016.

TEKIN, Yesim Bayoglu.; GUVEN, Suleyman.; KIRBAS, Aynur.; KALKAN, Yildiray.; TUMKAYA, Levent. et al. Is resveratrol a potential substitute for leuprolide acetate in experimental endometriosis? European Journal of Obstetrics \& Gynecology and Reproductive Biology, [s.I.], v. 184, p. 1-6, 2015.

U.S. DEPARTMENT OF HEALTH AND HUMAN SERVICES AND U.S. Department of Agriculture. 2015 - 2020 Dietary Guidelines for Americans. 8th Edition. [s.I.], 2015. Disponível em: < https://health.gov/our-work/food-nutrition/2015-2020-dietaryguidelines>. Acesso em: 6 out. 2020.

UNIVERSIDADE DE SÃO PAULO (USP). Tabela Brasileira de Composição de Alimentos (TBCA). Food Research Center (FoRC). Versão 7.1. São Paulo, 2020. Disponível em: < http://www.tbca.net.br/>. Acesso em: 29 out. 2020.

UNIVERSIDADE ESTADUAL DE CAMPINAS (UNICAMP). NÚCLEO DE ESTUDOS E PESQUISAS EM ALIMENTAÇÃO (NEPA). Tabela Brasileira de Composição de Alimentos (TACO), 4. ed. rev. e ampl. Campinas, 2011. 161 p. Disponível em: $<\mathrm{http}: / /$ www.nepa.unicamp.br/taco/contar/taco_4_edicao_ampliada_e_revisada.pdf? arquivo=taco_4_versao_ampliada_e_revisada.pdf>. Acesso em: 29 out. 2020. 
VALLÉE, Alexandre.; LECARPENTIER, Yves. Curcumin and Endometriosis. International Journal of Molecular Sciences, [s.I.], v. 21, 7th ed. p. 2440, 2020.

VITALE, Salvatore GIOVANNI.; Capriglione, STELLA.; Peterlunger, ISABEL.; La Rosa, VALENTINA Lucia.; VITAGLIANO, Amerigo. et al. The role of oxidative Stress and Membrane Transport Systems during Endometriosis: A Fresh Look at a Busy Corner. Oxidative Medicine and Cellular Longevity, [s.I.], v. 2018, 2018.

ZEKAVAT, Omid R.; KARIMI, Mohammad Y.; AMANAT, Aida.; ALIPOUR, Farzaneh. A randomised controlled trial of oral zinc sulphate for primary dysmenorrhoea in adolescent females. Australian and New Zealand Journal of Obstetrics and Gynaecology, [s.I.], v. 55, 4 th ed. p. 369-373, 2015.

Enviado: Janeiro, 2021.

Aprovado: Junho, 2021. 